\title{
Oral Nano Drug Delivery Systems for the Treatment of Type 2 Diabetes Mellitus: An Available Administration Strategy for Antidiabetic Phytocompounds
}

This article was published in the following Dove Press journal:

International Journal of Nanomedicine

\author{
Xin $\mathrm{Nie}^{1}$ \\ Zhejie Chen ${ }^{2}$ \\ Lan Pang' \\ Lin Wang \\ Huajuan Jiang' \\ Yi Chen' \\ Zhen Zhang' \\ Chaomei Fu' \\ Bo Ren' \\ Jinming Zhang' \\ 'College of Pharmacy, Chengdu \\ University of Traditional Chinese \\ Medicine, Chengdu 61 II37, People's \\ Republic of China; ${ }^{2}$ State Key Laboratory \\ of Quality Research in Chinese Medicine, \\ Institute of Chinese Medical Sciences, \\ University of Macau, Macao, 999087, \\ People's Republic of China
}

\begin{abstract}
In view of the worldwide serious health threat of type 2 diabetes mellitus (T2DM), natural sources of chemotherapies have been corroborated as the promising alternatives, with the excellent antidiabetic activities, bio-safety, and more cost-effective properties. However, their clinical application is somewhat limited, because of the poor solubility, instability in the gastrointestinal tract (GIT), low bioavailability, and so on. Nowadays, to develop nanoscaled systems has become a prominent strategy to improve the drug delivery of phytochemicals. In this review, we primarily summarized the intervention mechanisms of phytocompounds against T2DM and presented the recent advances in various nanosystems of antidiabetic phytocompounds. Selected nanosystems were grouped depending on their classification and structures, including polymeric NPs, lipid-based nanosystems, vesicular systems, inorganic nanocarriers, and so on. Based on this review, the state-of-the-art nanosystems for phytocompounds in T2DM treatment have been presented, suggesting the preponderance and potential of nanotechnologies.
\end{abstract}

Keywords: type 2 diabetes mellitus (T2DM), phytocompounds, drug delivery systems, nanoparticles (NPs), antidiabetic effects

\section{Introduction}

Diabetes mellitus, a chronic lifelong metabolic disorder, is a major global health issue that has reached alarming levels. ${ }^{1}$ According to the latest data from the International Diabetes Federation, approximately 463 million adults worldwide are currently suffering from diabetes. Without sufficient action to control the pandemic, 578 million people will live with diabetes by 2030. By 2045, the number will jump to an astonishing 700 million. $^{2} \mathrm{~T} 2 \mathrm{DM}$ is the most common type of diabetes. It has been estimated that nearly $95 \%$ of diabetic patients in the world have T2DM., ${ }^{3,4}$ The major pathogenesis of T2DM is insufficient insulin secretion from $\beta$ cells under the background of insulin resistance. After insulin being produced by the pancreas, it cannot be efficiently utilized by the cells, which is named "insulin resistance". $52 \mathrm{DM}$ is characterized by high levels of blood glucose called hyperglycemia. Long-term hyperglycemia results in the glycation of proteins that in turn leads to secondary complications, ${ }^{6}$ including retinopathy, cardiovascular disease, diabetic foot, neuropathy, and nephropathy. As a consequence, the quality
Correspondence: Jinming Zhang; Bo Ren Email cdutcmzjm@I26.com; renbo@cdutcm.edu.cn
International Journal of Nanomedicine 2020:I5 I02I5-10240

10215 
of life decreases and the risk of disability or even mortality increases. ${ }^{7,8}$ Frustratingly, there is no cure for T2DM. ${ }^{9}$ At present, the therapeutic strategies for T2DM mainly include regular physical exercise, proper lowcarbohydrate diets, and adherence to long-term medication therapy, like the oral administration of chemical hypoglycemic drugs and the injection of insulin. ${ }^{4}$ However, most diabetes medications promote weight gain, gastrointestinal disturbances, ${ }^{10}$ diarrhea, renal failure, hypersensitivity, ${ }^{11}$ and there is a proportionate risk of hypoglycemia using them to achieve tight glycemic control. ${ }^{12,13}$ Drug resistance is another serious obstacle. For example, sulfonylureas lose their effectiveness after treatment for 6 years in approximately $44 \%$ of diabetics. ${ }^{14}$ Therefore, it is momentous to discover new antidiabetic candidates with greater safety but fewer side effects.

Plants have always been an exemplary source of ethnic medicines or natural drugs. Phytocompounds are natural components isolated from plants, which have been paid increased attention with progressively in-depth research of modern medicine in the field of alternative medicine. ${ }^{15}$ Nowadays, approximately $50 \%$ of the drugs approved by the Food and Drug Administration (FDA) are plantderived compounds or their derivatives. ${ }^{16}$ For instance, metformin, a biguanidine-type antidiabetic drug, is developed from galegine which is isolated from Galega officinalis L. (Fabaceae $)^{17}$ and is currently used as the first-line oral medication for T2DM treatment. ${ }^{18,19}$ Compared with conventional therapies, natural plant-derived agents are more affordable and accessible, with fewer side-effects, so pharmaceutical research is increasingly inclined to discover new antidiabetic drugs from plants. ${ }^{20,21}$ About 1200 plants have been claimed to contain antidiabetic compounds, and more than 400 plants and their bioactive compounds have been scientifically evaluated for T2DM treatment. ${ }^{21,22}$ Phytocompound-based therapies are able to be developed as new approaches to treat T2DM or as adjuvants to support the existing monotherapies.

Generally, oral administration is recognized as the easiest and most convenient way. It is preferred by the patients with chronic diseases who require repeated dosing, ${ }^{23}$ like T2DM patients, since the oral administration of therapeutic drugs shows good patient compliance without any pain and risk of needlestick injuries. However, the shortcomings of orally delivered phytocompounds, such as poor solubility, instability in the GIT, extremely low bioavailability, short half-life, and so on, restrain the translation of biological activities from in vitro evaluations to in vivo applications, ${ }^{24,25}$ so it is of paramount importance to design innovative oral delivery systems for diabetic patients. Nanomedicine has been proven to be able to effectively improve the oral delivery efficacy of compounds through circumventing various delivery restrictions. ${ }^{26}$ It has been reported that the uptake of nanostructures is 15 250 times greater than that of microparticles. ${ }^{27}$ Besides, nanostructures are always employed to sustain the release of encapsulated compounds in order to reduce dose and dosing frequency, thereby increasing patient compliance and minimizing side effects. ${ }^{28}$ At present, a comprehensive review covering various oral nano delivery systems of phytocompounds for T2DM treatment in the preclinical stage is not available. In this review, we aimed to systematically summarize and critically analyze phytocompound-based oral nano delivery systems for T2DM treatment in recent years, and identify their therapeutic effects supported by experimental evidence in vitro or/and in vivo. On this basis, researchers could apply excellent delivery systems to undeveloped antidiabetic phytocompounds to explore more therapeutic possibilities in the future.

\section{Main Antidiabetic Mechanisms of Phytocompounds}

It is common for people to use natural plant medicine to prevent and/or treat diabetes in Central America, Asia, and West Africa. ${ }^{29}$ According to an estimate published by the World Health Organization in 2008, about $80 \%$ of diabetic patients currently rely on medicinal plants for their successive treatments. ${ }^{29,30}$ A wide variety of phytocompounds derived from medicinal plants, including flavonoids, polyphenols, terpenoids, alkaloids, saponins, quinones, polysaccharides, etc., have been intensively investigated for their antidiabetic effects. ${ }^{14,29,31-34}$ The main mechanisms of phytocompounds for T2DM therapy might be based on four aspects involving certain key targets (Figure 1). ${ }^{35}$

\section{Reduction of Carbohydrate Decomposition and Glucose Absorption}

Polyphenols, terpenoids, and tannins display inhibitory effects on $\alpha$-glucosidase and $\alpha$-amylase, the major carbohydrate hydrolyzing digestive enzymes. ${ }^{36} \alpha$-Amylase hydrolyzes macromolecules like starch into oligoglucans. At the brush border of the small intestine, these substances are further degraded by $\alpha$-glucosidase into absorbable glucose and then permeate into blood circulation. ${ }^{37}$ 


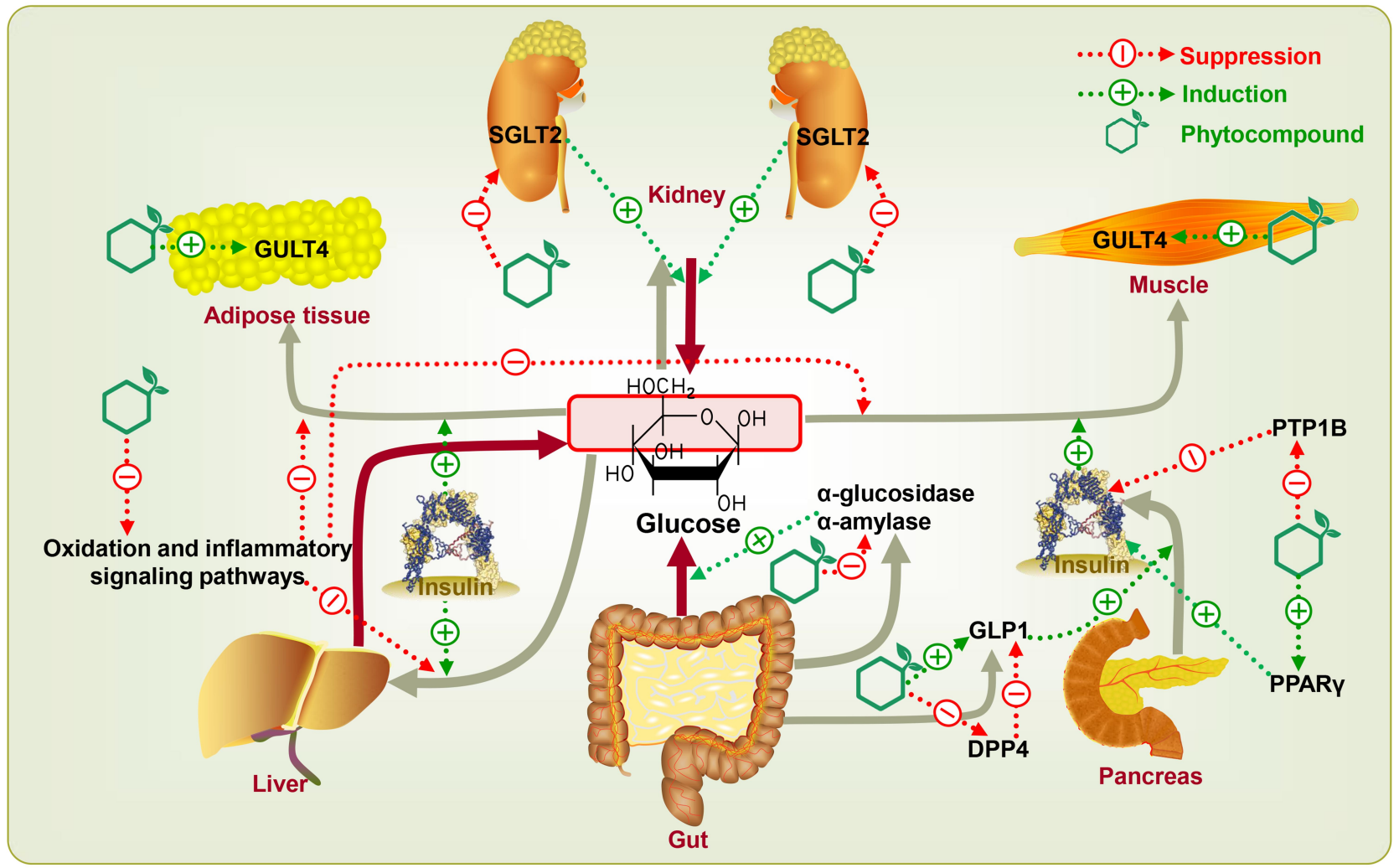

Figure I Multiple therapeutic targets of phytocompounds for T2DM treatment.

Under these conditions, phytocompounds can significantly reduce postprandial blood glucose levels by inhibiting $\alpha$ glucosidase and $\alpha$-amylase. ${ }^{36}$ Hyperglycemia may make the kidney reabsorb glucose above the normal level. ${ }^{38}$ Sodium-glucose co-transporter 2 (SGLT2) is the principal co-transporter of glucose reabsorption in the proximal convoluted tubule of the kidney. Phlorizin, chlorogenic acid, quercetin, kaempferol, kurarinone, and sophoraflavanone, with SGLT2 inhibitory activity, can promote the excretion of glucose in urine and suppress the reabsorption of glucose in the kidney. The excretion of glucose leads to a decrease of glucose in plasma levels, thus ameliorating all glycemic parameters. Typically, some synthetic compounds derived from phlorizin, including dapagliflozin, canagliflozin, ertugliflozin, and empagliflozin, have been approved by the FDA for T2DM treatment. ${ }^{39,40}$

\section{Promotion of Glucose Uptake and Metabolism}

Flavonoids and polyphenolic compounds can potentiate glucose transporter isoform 4 (GLUT4) expression as well as glucose uptake. ${ }^{41,42}$ GLUT4 is located at adipose tissue and skeletal muscle, which is mainly controlled by insulin secretion. Insulin stimulates the translocation of GLUT4 from an intracellular location to the cell surface, which can transport glucose into the inner and in turn decrease blood glucose levels. Pathologically, diabetic patients have lower expression of GLUT4. ${ }^{43}$ The abnormality of GLUT4 expression causes a malfunction in the glucose uptake system and eventually results in insulin resistance in T2DM. Sayem et $\mathrm{al}^{44}$ reviewed the action of phytocompounds on the modulation of GLUT4 translocation through insulin signaling pathways. For instance, berberine and vanillic acid improved the translocation of GLUT4 via adenosine 5'monophosphate-activated protein kinase (AMPK)dependent pathway whereas resveratrol via phosphatidylinositol 3-kinase (PI3K)-protein kinase B (Akt) pathway.

\section{Improvement of Insulin Action and Sensitivity}

Glucagon-like peptide 1 (GLP1), an incretin hormone, can stimulate postprandial insulin secretion. Dipeptidyl peptidase 4 (DPP4) is a GLP1-degrading enzyme. ${ }^{45,46}$ The evidence suggests that polyphenols such as chlorogenic acid, epicatechin, and syringic acid can stimulate the secretion of GLP1 from intestinal L-cells, increase the 
half-life of GLP1 by inhibiting DPP4, stimulate the secretion of insulin from $\beta$-cells, irritate the peripheral response to insulin, and ultimately result in improving the overall effects of the GLP1-insulin axis. ${ }^{45}$ Phytocompounds can also regulate insulin sensitivity via the blockage of protein tyrosine phosphatase 1B (PTP1B) and the stimulation of peroxisome proliferator-activated receptor $\gamma$ (PPAR $\gamma)$. PTP1B is an enzyme responsible for reversing the autophosphorylation of the insulin receptor. The inhibition of PTP1B results in a prolonged insulin signaling cascade, thereby increasing insulin sensitivity. ${ }^{47}$ Researches have reported approximately 500 PTP1B inhibitors (248 phenolics, 159 terpenoids, 40 alkaloids, 24 fatty acids, and 17 steroids) isolated from 100 species of natural sources. These phytocompounds could be developed as antidiabetic drugs or at least as promising drug candidates in the near future. ${ }^{48}$ PPAR $\gamma$ is the predominant molecular target of the thiazolidinedione class of insulin-sensitizing drugs like pioglitazone, troglitazone, and rosiglitazone. ${ }^{49}$ Many in vivo studies have implied that some natural product activators of PPAR $\gamma$ like honokiol, amorphastilbol, amorfrutin 1, and amorfrutin B have similar effects on stimulating glucose uptake as full thiazolidinedione agonists, but with reduced side effects. ${ }^{50,51}$

\section{Antioxidant and Antiinflammatory Actions}

The oxidation and inflammatory responses can establish a causal relationship in the occurrence of T2DM, which further leads to insulin resistance, or oxidation and inflammatory responses may be augmented by the hyperglycemic state, which results in T2DM-related complications. ${ }^{52-58}$ Recently, Ahangarpour et $\mathrm{al}^{58}$ and Gothai et $\mathrm{al}^{57}$ reviewed the research progress of phytocompounds, including chlorogenic acid, ellagic acid, curcumin, resveratrol, apigenin, quercetin, naringenin, catechin, etc., ameliorating insulin resistance and diabetic complications by suppressing oxidation or/and inflammatory signaling pathways. Phytocompounds can not only treat diabetes but also reduce the risk of T2DMassociated complications, which is a very attractive feature.

\section{The Necessity of Developing} Antidiabetic PhytocompoundsLoaded Nano Drug Delivery Systems

Despite the promising pharmacological activities of various phytocompounds, there are still some difficulties in translating their beneficial effects via oral route in clinical practice. ${ }^{59}$ A review of clinical trials showed that the dose of phytocompounds for diabetes treatment was a crucial variable affecting clinical response. ${ }^{60}$ In most studies, higher doses of phytocompounds exhibited better curative activity which may be due to the low bioavailability. Improving oral bioavailability plays a key role in further clinical applications. The way to overcome the low bioavailability of phytocompounds through higher doses showed better efficacy but simultaneously caused toxicity in several organs. ${ }^{60}$ This is because the apparent volume of distribution of phytocompounds is quite large, which results in a large accumulation of drugs in normal organs, thus increasing undesired side effects. ${ }^{61}$ There is another problem with antidiabetic phytocompounds. Because of the low stability of phytocompounds in the process of absorption, they have a lower potential antidiabetic effect in vivo. ${ }^{62}$ Great attempts have been made to develop delivery systems in order to overcome these critical shortcomings.

Conventional drug delivery systems like microspheres, ${ }^{63,64}$ microemulsions, ${ }^{65}$ amorphous solid dispersion, ${ }^{66,67} \beta$ Cyclodextrin, ${ }^{68} \mathrm{pH}$-sensitive hydrogels ${ }^{69}$ have been used to deliver antidiabetic phytocompounds for T2DM treatment. However, conventional drug delivery systems always have some restrictions, such as lack of curative effect because of ineffective or improper dose, diminished potency or altered effects because of drug metabolism, and lack of precise target specificity. More and more researches are focused on nano delivery systems. ${ }^{70}$ In the past two decades, several nanotherapeutics have been approved by the FDA for the treatment of diabetes, high cholesterol, cancer, hepatitis, neurological diseases, autoimmune diseases, cardiovascular diseases, Parkinson's disease, and certain infectious diseases. ${ }^{71}$ Oral nano delivery systems can not only protect antidiabetic phytocompounds from enzymatic and/or chemical degradation in GIT but also provide other benefits, such as avoidance of firstpass metabolism, improvement of pharmacokinetic and pharmacodynamic profile, fast onset of action, targeted drug delivery, sustained drug release, lower dose and dosing frequency, and fewer side effects. ${ }^{2}$

\section{Oral Nano Drug Delivery Systems of Antidiabetic Phytocompounds}

This section will focus on different types of oral nano delivery systems of antidiabetic phytocompounds 
(Table 1) (Figure 2), their impact on pharmacokinetic parameters, and their therapeutic effects.

\section{Polymeric NPs}

NPs are colloidal drug delivery systems that cover particles ranging from $10 \mathrm{~nm}$ to $1000 \mathrm{~nm}$ in diameter. They can be a reservoir system in which drugs are enclosed in a cavity surrounded by polymeric membranes called nanocapsules or as a matrix system in which drugs are dispersed throughout particles called nanospheres (Figure 2). ${ }^{2}$ Polymers have attracted much attention in therapeutic applications because of the design flexibility based on functionalization, polymer diversity, and macromolecular synthesis methods. ${ }^{117}$ According to the different materials used to construct them, polymer-based delivery systems can be divided into synthetic polymer NPs and inartificial polymer NPs. ${ }^{2}$

\section{NPs Based Upon Inartificial Polymers}

Inartificial polymers have the characteristics of low cost in processing and high abundance in nature. ${ }^{118}$ Non-toxicity and biocompatibility are the primary advantages of inartificial polymers as compared to synthetic polymers. ${ }^{119}$ Sodium alginate, chitosan, gum arabica, gum rosin, and dextran are the inartificially occurring polymers that have been developed for the delivery of antidiabetic phytocompounds.

\section{Chitosan-Based NPs}

Chitosan, a kind of polycationic polysaccharide, is produced by alkaline deacetylation of chitin ${ }^{120}$ which is derived from the cell walls of fungi, the cuticle of insects, and the exoskeleton of crustaceans. ${ }^{121,122}$ By far, chitosan is the most extensively used for the delivery of antidiabetic phytocompounds due to its easy surface modification, property to blend with multitudinous polymers, non-immunogenicity as well as non-toxicity, and significant compatibility with cells and tissues. ${ }^{123}$ A bottom-up ionic gelation method was applied to prepare chitosan NPs encapsulating ferulic $\operatorname{acid}^{72}$ or curcumin. ${ }^{124}$ Chauhan et $\mathrm{al}^{124}$ reported, in L6 rat skeletal muscle cells in vitro, curcumin chitosan NPs exhibited a superior effect on the translocation of GLUT4 to the cell surface as compared to free curcumin. In another study of Panwar et al, ${ }^{72}$ ferulic acid chitosan NPs showed fourfold enhanced oral bioavailability in vivo compared with free ferulic acid and displayed better antidiabetic potential in streptozotocin (STZ)-induced diabetic rats than ferulic acid. This might be attributed to the unique ability of chitosan to temporarily open the tight junctions between epithelial cells. $^{125}$ Moreover, the high positive charge of chitosan makes it well suitable for oral drug delivery because it enhances the adhesion to negatively charged mucosal surfaces, thereby increasing the uptake of cells. ${ }^{126}$ Besides, the $-\mathrm{OH}$ and $-\mathrm{NH}_{2}$ active groups on the chitosan molecule are prone to chemical reactions. ${ }^{127} \mathrm{Zhu}$ et al investigated the grafting of catechin onto chitosan using hydrogen peroxide $\left(\mathrm{H}_{2} \mathrm{O}_{2}\right)$ and ascorbic acid $(\mathrm{Vc})$ as redox initiator in acetic acid solution. ${ }^{128}$ In vitro antidiabetic activity revealed that the inhibitory effect of $\alpha$-glucosidase decreased in the order of catechin-g-chitosan $>$ catechin $>$ acarbose $>$ chitosan, and the inhibitory effect of $\alpha$-amylase decreased in the order of acarbose $>$ catechin-g-chitosan $>$ catechin $>$ chitosan. Although chitosan possesses favorable biological properties, it is rarely used alone for oral drug administration because chitosan as a carrier is subject to leak out the entrapped drugs as it dissolves easily in acidic conditions. $^{125,129}$

\section{Alginate/Chitosan-Based NPs}

Another inartificial polymer sought with chitosan is alginate. Alginate is a hydrophilic anionic copolymer broadly distributed in the cell walls of brown algae. The wide pharmaceutical applicability of alginate is owing to its unique ability to form gels in aqueous medium or at low $\mathrm{pH}$ under the presence of divalent cations like calcium ions. ${ }^{130}$ Alginate and chitosan are able to form polyelectrolyte complexes through electrostatic interactions between oppositely charged groups. ${ }^{125}$ The poor solubility of alginate network at low $\mathrm{pH}$ decreases the high solubility of chitosan at low $\mathrm{pH}$, while chitosan which is less soluble at high $\mathrm{pH}$ stabilizes alginate which is more soluble at high $\mathrm{pH} .{ }^{118}$ The alginate/chitosan complex protects the encapsulated phytocompounds and effectively slows down the release than either chitosan or alginate alone. For instance, in vitro assays, the chitosan-alginate polyelectrolyte complex prolonged the average release time of curcumin by $40 \mathrm{~min}$ in simulated gastric fluid and concurrently reduced the loss of curcumin by $20 \%$. Besides, the curcumin nanoformulation prepared by chitosanalginate complex had a 30\% higher glucose-lowering effect in vivo than that prepared by chitosan only. ${ }^{73}$ Maity et $\mathrm{al}^{74}$ prepared a novel alginate coated chitosan core-shell nanocarrier system which was effectively used in the oral delivery of naringenin to STZ-induced diabetic rats. The innovation spot lied in its structural chemistry because the core-shell construction was designed to 
Table I Oral Nano Delivery Systems Of Antidiabetic Phytocompounds For T2DM Treatment Investigated in vivo ( $\uparrow$ ) Increase, $(\downarrow)$ Decrease

\begin{tabular}{|c|c|c|c|c|c|}
\hline $\begin{array}{l}\text { Drug Delivery } \\
\text { System }\end{array}$ & Phytocompound & $\begin{array}{l}\text { Dose (mgl } \\
\text { kg b.w) }\end{array}$ & Size (nm) & Outcomes in vivo & Reference \\
\hline Chitosan NPs & Ferulic acid & 10 & $119.5 \pm 3.9$ & $\begin{array}{l}\text { Bioavailability } \uparrow \text {; Glucose lowering effects } \uparrow ; \\
\text { Antihyperlipidemic effects } \uparrow\end{array}$ & [72] \\
\hline $\begin{array}{l}\text { Chitosan-alginate } \\
\text { NPs }\end{array}$ & Curcumin & 50 & $<50$ & $\begin{array}{l}\text { Hepatic glycogen } \uparrow \text {; Glucose lowering effects } \uparrow \text {; } \\
\text { Deposition of curcumin in the liver } \uparrow\end{array}$ & [73] \\
\hline $\begin{array}{l}\text { Chitosan-alginate } \\
\text { NPs }\end{array}$ & Naringenin & 50 & $216.44 \pm 0.6$ & $\begin{array}{l}\text { Glucose lowering effects } \uparrow \text {; Normalization of pancreatic } \\
\text { and hepatic abnormalities } \uparrow \text {; Prevention of glycation- } \\
\text { induced iron-mediated oxidative stress } \uparrow \text {; No toxicity }\end{array}$ & [74] \\
\hline $\begin{array}{l}\text { Chitosan-alginate } \\
\text { NPs }\end{array}$ & Quercetin & 100 & $91.58 \pm 1.14$ & $\begin{array}{l}\text { Glucose lowering effects } \uparrow \text {; Antihyperlipidemic effects } \uparrow \text {; } \\
\text { No toxicity }\end{array}$ & [75] \\
\hline $\begin{array}{l}\text { Gum rosin } \\
\text { nanocapsules }\end{array}$ & Thymoquinone & $\begin{array}{l}20 \text { and } 40 \\
\text { and } 80\end{array}$ & 70.21 & $\begin{array}{l}\text { Glucose lowering effects } \uparrow \text {; Antihyperlipidemic effects } \uparrow \text {; } \\
\text { HbAIc level } \downarrow\end{array}$ & [76] \\
\hline $\begin{array}{l}\text { Chitosan-gum } \\
\text { arabica NPs }\end{array}$ & Glycyrrhizin & 20 and 40 & 181.4 & Glucose lowering effects $\uparrow ;$ Antihyperlipidemic effects $\uparrow$ & [77] \\
\hline PLGA NPs & Quercetin & 150 & $179.9 \pm 11.2$ & $\begin{array}{l}\text { Bioavailability } \uparrow \text {; Sustained release; Glucose lowering } \\
\text { effects } \uparrow \text {; Antioxidant effects } \uparrow\end{array}$ & [78] \\
\hline PLGA NPs & $\gamma$-oryzanol & 320 & $214.8 \pm 4.3$ & $\begin{array}{l}\text { Glucose lowering effects } \uparrow ; \text { Antihyperlipidemic effects } \uparrow \text {; } \\
\text { Antiinflammation effects } \uparrow \text {; Regulation of hypothalamus } \\
\text { and pancreatic islets dysfunction }\end{array}$ & [79] \\
\hline PLA NPs & Lutein & 25 and 50 & 152.38 & $\begin{array}{l}\text { Glucose lowering effects } \uparrow \text {; Antihyperlipidemic effects } \uparrow \\
\text { Antioxidant effects } \uparrow\end{array}$ & [80] \\
\hline PLA-PEG NPs & Curcumin & 20 & 117 & $\begin{array}{l}\text { Glucose lowering effects } \uparrow ; \text { Plasma insulin lever } \uparrow \\
\text { Antiinflammation effects } \uparrow ;\end{array}$ & [8I] \\
\hline NEs & $\begin{array}{l}\text { Bitter gourd seed } \\
\text { oil }\end{array}$ & - & $93.9 \pm 2.6$ & Glucose lowering effects $\uparrow ;$ Antioxidant effects $\uparrow$ & [82] \\
\hline NEs & Berberine & $\begin{array}{l}25 \text { and } 50 \\
\text { and } 100\end{array}$ & $30.56 \pm 0.35$ & $\begin{array}{l}\text { Bioavailability } \uparrow \text {; Glucose lowering effects } \uparrow \text {; Regulation of } \\
\text { liver function }\end{array}$ & [83] \\
\hline NEs & Sage Essential Oil & 100 & 143.2 & $\begin{array}{l}\text { Glucose lowering effects } \uparrow \text {; Regeneration of pancreatic } \\
\text { tissue }\end{array}$ & [84] \\
\hline NEs & $\alpha$-tocopherol & 30 & $85 \pm 0.8$ & $\begin{array}{l}\text { Bioavailability } \uparrow \text {; Limited glucose lowering effects; } \\
\text { Antioxidant effects } \uparrow\end{array}$ & [85] \\
\hline SNEDDS & Polypeptide-k & 400 and 800 & 31.89 & $\begin{array}{l}\text { Glucose lowering effects } \uparrow ; \text { Antioxidant effects } \uparrow \text {; } \\
\text { Antihyperlipidemic effects } \uparrow \text {; Regeneration of pancreatic } \\
\text { tissue }\end{array}$ & [86] \\
\hline SNEDDS & $\begin{array}{l}\text { Polypeptide-k and } \\
\text { Curcumin }\end{array}$ & $\begin{array}{l}\text { Polypeptide- } \\
\text { k:400 and } \\
\text { Curcumin:40 } \\
\text { Polypeptide- } \\
\text { k:200 and } \\
\text { Curcumin:20 }\end{array}$ & 75.4 & $\begin{array}{l}\text { Glucose lowering effects } \uparrow ; \text { Antihyperlipidemic effects } \uparrow \text {; } \\
\text { Antioxidant effects } \uparrow ; \text { Regeneration of pancreatic tissue }\end{array}$ & [87] \\
\hline SNEDDS & Resveratrol & 10 and 20 & $336 \pm 11.6$ & Glucose lowering effects $\uparrow$; Antihyperlipidemic effects $\uparrow$ & [88] \\
\hline
\end{tabular}

(Continued) 
Table I (Continued).

\begin{tabular}{|c|c|c|c|c|c|}
\hline $\begin{array}{l}\text { Drug Delivery } \\
\text { System }\end{array}$ & Phytocompound & $\begin{array}{l}\text { Dose }(\mathrm{mg} / \\
\mathrm{kg} \text { b.w) }\end{array}$ & Size (nm) & Outcomes in vivo & Reference \\
\hline SNEDDS & $\begin{array}{l}\text { Trans-cinnamic } \\
\text { acid }\end{array}$ & 80 & 28 & $\begin{array}{l}\text { Bioavailability } \uparrow \text {; Glucose lowering effects } \uparrow ; \\
\text { Antihyperlipidemic effects } \uparrow \text {; Activities of ALT and AST } \uparrow\end{array}$ & [89] \\
\hline SLNs & Myricitrin & $\begin{array}{l}1 \text { and } 3 \text { and } \\
10\end{array}$ & $50-150$ & $\begin{array}{l}\text { Antioxidant effects } \uparrow \text {; Glucose lowering effects } \uparrow ; \beta \text {-cell's } \\
\text { function index } \uparrow \text {; Skeletal muscle glycogen content } \uparrow \text {; GLUT4 } \\
\text { gene expression } \uparrow \text {; Insulin resistance } \downarrow ; \text { Pancreas apoptosis } \downarrow\end{array}$ & [90] \\
\hline SLNs & Resveratrol & 10 & 248 & $\begin{array}{l}\text { Antioxidant effects } \uparrow \text {; Glucose lowering effects } \uparrow \text {; Insulin } \\
\text { resistance } \downarrow \text {; Expression of Snap23, Stx } 4 \text {, and Vamp } 2 \uparrow\end{array}$ & [9I] \\
\hline SLNs & Berberine & 50 and 100 & 76.8 & $\begin{array}{l}\text { Bioavailability } \uparrow \text {; Glucose lowering effects } \uparrow \text {; Glucose } \\
\text { tolerance } \uparrow \text {; Insulin sensitivity } \uparrow \text {; Islet function } \uparrow \text {; }\end{array}$ & [92] \\
\hline SLNs & Berberine & 50 and 100 & 76.8 & $\begin{array}{l}\text { Predominant accumulation of curcumin in the liver; } \\
\text { Hepatosteatosis } \downarrow\end{array}$ & [93] \\
\hline NLCs & Silymarin & 38.13 & $\begin{array}{l}\text { SLM-NLCs- } \\
\text { CP: } 265.9 \pm \\
13.4 \\
\text { SLM-NLCs- } \\
\text { SA: } 213.6 \pm \\
16.0\end{array}$ & $\begin{array}{l}\text { Glucose lowering effects } \uparrow \text {; TG levels } \downarrow \text {; No toxicity; } \\
\text { Antihyperalgesic effects }\end{array}$ & {$[94,95]$} \\
\hline NLCs & Baicalin & 200 & $92 \pm 3.1$ & Glucose lowering effects $\uparrow ;$ TC, TG, and HbAlc levels $\downarrow$ & [96] \\
\hline Liposomes & Betanin & 20 & $40.06 \pm 6.21$ & $\begin{array}{l}\text { Antioxidant effects } \uparrow \text {; Glucose lowering effects } \uparrow \text {; Serum } \\
\text { insulin levels } \uparrow \text {; Antihyperlipidemic effects } \uparrow \text {; Prevention of } \\
\text { damage in kidney, liver and pancreas }\end{array}$ & [97] \\
\hline Niosomes & Lycopene & 100 and 200 & $202 \pm 41$ & Glucose lowering effects $\uparrow ;$ Antihyperlipidemic effects $\uparrow$; & [98] \\
\hline Niosomes & Embelin & - & $500-734$ & Glucose lowering effects $\uparrow ;$ Antioxidant effects $\uparrow$ & [99] \\
\hline Niosomes & Gymnemic acid & 100 and 200 & 138.8 & $\begin{array}{l}\text { Glucose lowering effects } \uparrow \text {; Antihyperlipidemic effects } \uparrow \text {; } \\
\text { Antioxidant effects } \uparrow \text {; Antiinflammation effects } \uparrow ; \\
\text { Antiglycation (AGEs) effect } \uparrow\end{array}$ & {$[100]$} \\
\hline Phytosomes & Berberine & 100 & $165.2 \pm 5.1$ & $\begin{array}{l}\text { Bioavailability } \uparrow \text {; Glucose lowering effects } \uparrow \text {; } \\
\text { Antihyperlipidemic effects } \uparrow\end{array}$ & {$[101]$} \\
\hline Micelles & Amentoflavone & 200 & $58.44 \pm 2.21$ & $\begin{array}{l}\text { Bioavailability } \uparrow \text {; Glucose lowering effects } \uparrow \text {; Insulin } \\
\text { sensitivity } \uparrow \text {; Antihyperlipidemic effects } \uparrow \text {; } \\
\text { Antiinflammation effects } \uparrow \text {; Protein and mRNA } \\
\text { expressions of PPAR } \gamma \text {, and GLUT4 } \uparrow\end{array}$ & [102] \\
\hline Micelles & Quercetin & 50 & $85-108$ & $\begin{array}{l}\text { Bioavailability } \uparrow \text {; Glucose lowering effects } \uparrow \text {; Antioxidant } \\
\text { effects } \uparrow\end{array}$ & [103] \\
\hline Micelles & Silymarin & 50 & $247 \pm 11$ & $\begin{array}{l}\text { Glucose lowering effects } \uparrow \text {; Insulin level } \uparrow \\
\text { Antihyperlipidemic effects } \uparrow \text {; Antioxidant effects } \uparrow \text {; Gene } \\
\text { expression of PdxI and Nkx6.I } \uparrow ; \beta \text {-cell regeneration } \uparrow \text {; } \\
\text { Prevention of damage in liver }\end{array}$ & [104] \\
\hline Micelles & Curcumin & 100 & $333 \pm 6$ & $\begin{array}{l}\text { Glucose lowering effects } \uparrow \text {; Antihyperlipidemic effects } \uparrow \text {; } \\
\text { Antioxidant effects } \uparrow \text {; Gene expression of insulin, PdxI } \\
\text { and Nkx6.I } \uparrow \text {; Prevention of damage in liver }\end{array}$ & [105] \\
\hline
\end{tabular}


Table I (Continued).

\begin{tabular}{|c|c|c|c|c|c|}
\hline $\begin{array}{l}\text { Drug Delivery } \\
\text { System }\end{array}$ & Phytocompound & $\begin{array}{l}\text { Dose }(\mathrm{mg} / \\
\mathrm{kg} \text { b.w) }\end{array}$ & Size (nm) & Outcomes in vivo & Reference \\
\hline Micelles & Curcumin & $100 \mu g$ & - & $\begin{array}{l}\text { Bioavailability } \uparrow \text {; Glucose lowering effects } \uparrow \text {; } \\
\text { Antihyperlipidemic effects } \uparrow \text {; Prevention of damage in } \\
\text { kidney, liver and pancreas; No toxicity; } \beta \text {-cell } \\
\text { regeneration } \uparrow ; \text { Wound healing effects } \uparrow\end{array}$ & [106] \\
\hline Zinc oxide NPs & $\begin{array}{l}\text { Docosahexaenoic } \\
\text { acid }\end{array}$ & 10 & 90 & $\begin{array}{l}\text { Glucose lowering effects } \uparrow \text {; Insulin lever } \uparrow \text {; Insulin } \\
\text { resistance } \downarrow \text {; Antioxidant effects } \uparrow \text {; Improvement of } \\
\text { erythrocyte membrane fatty acids; PI3K level } \downarrow \text {; } \\
\text { Antihyperlipidemic effects } \uparrow\end{array}$ & [107] \\
\hline Selenium NPs & $\begin{array}{l}\text { Catathelasma } \\
\text { ventricosum } \\
\text { polysaccharides }\end{array}$ & $\begin{array}{l}0.5 \text { and } 2 \\
\text { and } 4\end{array}$ & 49.73 & $\begin{array}{l}\text { Glucose lowering effects } \uparrow \text {; Antioxidant effects } \uparrow \text {; } \\
\text { Antihyperlipidemic effects } \uparrow\end{array}$ & [108] \\
\hline $\begin{array}{l}\text { Selenium-coated } \\
\text { NLCs }\end{array}$ & Berberine & 50 & 161.2 & Bioavailability $\uparrow$; Glucose lowering effects $\uparrow$ & [109] \\
\hline $\begin{array}{l}\text { Mesoporous } \\
\text { silica NPs }\end{array}$ & $\begin{array}{l}\text { 16- } \\
\text { Hydroxycleroda- } \\
\text { 3,13-Dine-16,15- } \\
\text { Olid }\end{array}$ & 10 and 30 & $258 \pm 5.7$ & Glucose lowering effects $\uparrow ; \mathrm{TG}, \mathrm{GOT}$, and CHOL levels & [110] \\
\hline Nanocrystals & Curcumin & 15 & 32 & $\begin{array}{l}\text { Glucose lowering effects } \uparrow \text {; Gene expression and } \\
\text { activities of insulin and insulin receptor } \uparrow\end{array}$ & {$[1111]$} \\
\hline Nanocrystals & Curcumin & 6 and 12 & $40-50$ & $\begin{array}{l}\text { Glucose lowering effects } \uparrow \text {; Insulin level } \uparrow \text {; Antioxidant } \\
\text { effects } \uparrow\end{array}$ & [112] \\
\hline Nanosuspensions & Ursolic acid & 25 and 50 & 246.4 & $\begin{array}{l}\text { Glucose lowering effects } \uparrow ; \text { Antioxidant effects } \uparrow \\
\text { Antihyperlipidemic effects } \uparrow\end{array}$ & [113] \\
\hline Nanosuspensions & Berberine & 50 & $73.1 \pm 3.7$ & Glucose lowering effects $\uparrow$; Antihyperlipidemic effects $\uparrow$ & [114] \\
\hline Nanosuspensions & Gymnemic Acids & 400 & - & $\begin{array}{l}\text { Glucose lowering effects } \uparrow \text {; Insulin level } \uparrow ; \\
\text { Antihyperlipidemic effects } \uparrow ; \text { tHb level } \uparrow ; \text { HbAIc level } \downarrow\end{array}$ & [115] \\
\hline Nanosuspensions & Betulin & 20 & 110 & Bioavailability $\uparrow$; Glucose lowering effects $\uparrow$ & [116] \\
\hline
\end{tabular}

Abbreviations: NPs, nanoparticles; HbAlc, glycosylated hemoglobin; PLGA, poly (lactic-co-glycolic acid); PLA, poly (lactic acid); PEG, poly (ethylene glycol); NEs, nanoemulsions; SNEDDS, self-nanoemulsifying drug delivery systems; ALT, alanine aminotransferase; AST, aspartate aminotransferase; SLNs, solid lipid NPs; GLUT4, glucose transporter isoform 4; Snap23, synaptosomal-associated protein 23; Stx4, syntaxin4; Vamp2, vesicle-associated membrane protein 2; NLCs, nanostructured lipid carriers; SLM-NLCs-CP, silymarin-loaded nanostructured lipid carriers produced with cetyl palmitate as solid lipid; SLM-NLCs-SA, silymarin-loaded nanostructured lipid carriers produced with stearic acid as solid lipid; TG, triglyceride; TC, total cholesterol; AGEs, advanced glycation end products; mRNA, messenger ribonucleic acid; PPAR $\gamma$, peroxisome proliferator-activated receptor $\gamma$; PdxI, pancreatic and duodenal homeobox I; Nkx6.I, NK6 homeobox I; PI3K, phosphatidylinositol 3-kinase; GOT, glutamate oxaloacetate transaminase; $\mathrm{CHOL}$, cholesterol; tHb, total hemoglobin.

decrease the particle size and assure efficient prevention of embedded naringenin from fast-pass metabolism through sheltering it within the core of NPs. Similarly, in another study of Mukhopadhyay et al, ${ }^{75}$ a $\mathrm{pH}$-sensitive polymeric NPs with core-shell-corona morphology for encapsulating quercetin were prepared by the use of succinyl chitosan and alginate. Succinyl chitosan and alginate show excellent $\mathrm{pH}$ sensitivity due to the presence of carboxyl groups $(-\mathrm{COOH})$ on their structure. The spherical nanoformulation could perform a $\mathrm{pH}$-sensitive controlled release of quercetin and follow an anomalous (non-Fickian) trend, no matter in vitro or in vivo studies. Compared with native phytocompounds, both core-shell NPs exerted pronounced hypoglycemic effects and effective maintenance of glucose homeostasis in STZ-induced diabetic rats. Besides, both NPs displayed no toxicity in vivo.

\section{Gum-Based NPs and Gum/Chitosan-Based NPs}

Natural gums, like guar gum, gellan gum, karaya gum, gum acacia, locust bean gum, konjac gel, or xanthan gums 


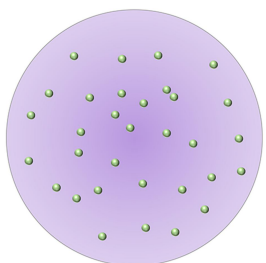

Nanospheres

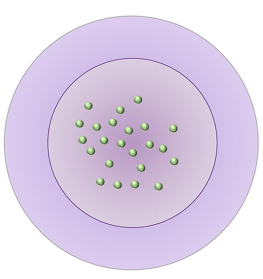

Nanocapsules

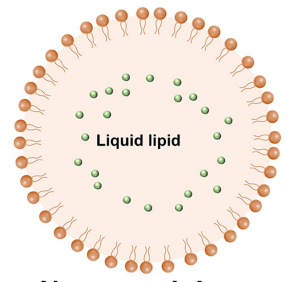

Nanoemulsions

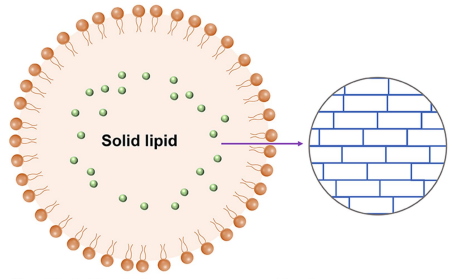

Solid lipid nanoparticles

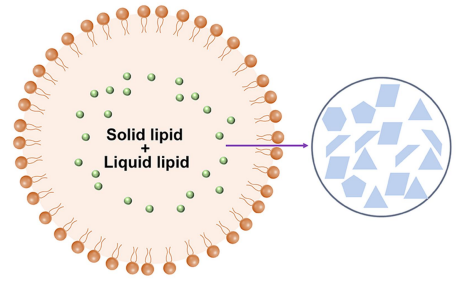

Nanostructured lipid carriers

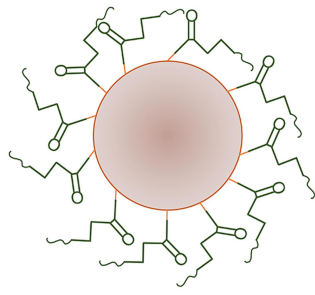

Metallic nanoparticles

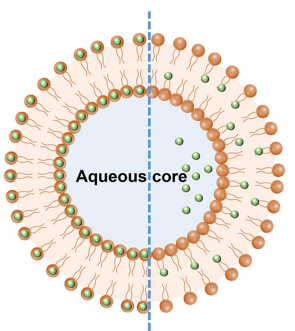

Phytosomes Liposomes

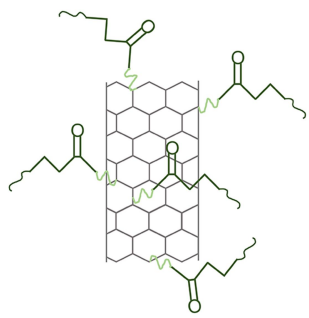

Carbon nanotubes

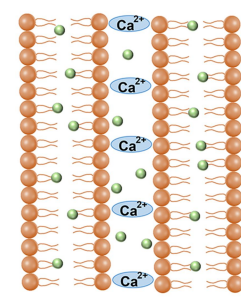

Nanocochleates

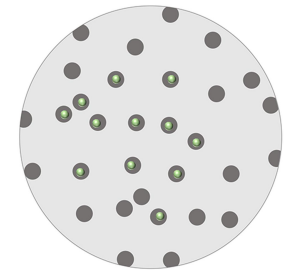

Mesoporous silica nanoparticles

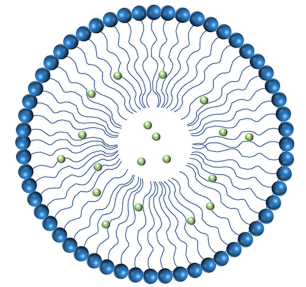

Micelles
- Phytocompounds

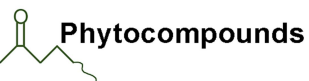

Amphiphilic polymer

Amphiphilic polymer

Figure 2 Different types of oral nano delivery systems of antidiabetic phytocompounds for T2DM treatment.

have been extensively employed to develop friendly drug delivery systems. They have the capacity to form hydrogels when exposed to water and show high stability in a broad $\mathrm{pH}$ range. ${ }^{131}$ Gum rosin is an inartificial anionic polymer derived from pine trees. ${ }^{132}$ Rani et $\mathrm{al}^{76}$ developed thymoquinone-loaded gum rosin nanocapsules using the nanoprecipitation method, also called the solvent displacement method. Thymoquinone nanoformulations contained only half the amount administrated as native thymoquinone but performed a better antihyperglycemic activity in type 2 diabetic rats. Rani et al ${ }^{77}$ chose gum arabica and chitosan as basic polymers for the preparation of the glycyrrhizin-loaded NPs which were synthesized by the electrostatic interaction of negatively charged carboxylic groups $(-\mathrm{COO})$ of gum arabica with positively charged amine group (-NH2) of chitosan. Glycyrrhizin-loaded NPs exerted striking antihyperglycemic and antihyperlipidemic effects in type 2 diabetic rats, which were comparable to the standard antidiabetic drug, metformin. In another study of Rani et al, ${ }^{133}$ two kinds of nanoformulations discussed above were mixed to explore their combined effects.
Compared with the single nanoformulation, even at a decreased drug load, combined nanoformulations exhibited significant improvement on antidiabetic activity in vivo as proven by encouraging responses in all eight tested parameters.

\section{Dextran-Based NPs}

Dextran is a highly water-soluble polysaccharide with negatively charged. It predominantly contains linear $\alpha-1,6$-linked glucopyranose units and some degree of 1.3-branching. ${ }^{134}$ Dextran mainly comes from the sucrose-rich environment of Lactobacillus, Streptococcus, and Leuconostoc. ${ }^{135}$ Because of the low affinity between hydrophilic polymeric matrix and lipophilic drugs, drug encapsulation is difficult. Kapoor et al $^{136}$ modified dextran by connecting hexadecyl chains with ether bonds to make it amphiphilic. This synthesized O-hexadecyl-dextran could self-assemble in aqueous media, enclosing berberine into the hydrophobic pockets, fabricating NPs. In vitro study on primary hepatocytes, berberine-loaded O-hexadecyl-dextran NPs, even at a 20-fold reduced concentration, were as efficient as berberine in preventing high 
glucose-induced oxidative stress, mitochondrial depolarization as well as downstream events of apoptotic cell death.

Despite their highly biodegradable, the limitation of inartificial polymers is their batch-to-batch variability because they are usually extracted from different species, regions, and under various climatic conditions, which makes them less attractive than synthetic polymers that are more versatile and reproducible. ${ }^{137}$

\section{NPs Based Upon Synthetic Polymers}

Unlike the inartificial polymers, synthetic polymers are available in a large variety compositions with desirable properties, the ease of control over the synthetic processes, and batch-to-batch reproducibility. ${ }^{2,135,138}$ Synthetic polymer NPs usually consist of poly (vinyl alcohol) (PVA), poly ( $\varepsilon$-caprolactone) (PCL), poly (lactic acid) (PLA), poly (lactic-co-glycolic acid) (PLGA), and poly (methyl methacrylate) (PMMA), which are approved by the FDA due to their biodegradability and biocompatibility. ${ }^{1,139}$ Polyesters are applied in amphiphilic diblock copolymers where the versatility provided by changing the compositions and adjusting the block lengths can make changes in drug loading capacity, carrier size, and drug release. ${ }^{140}$

\section{PLGA-Based NPs}

At first, PLGA acted as clinical suture materials because they could be thoroughly absorbed by the body. PLGA-based particles have been utilized as carriers for more than 15 small molecular drugs approved by the FDA. ${ }^{137}$ PLGA polymers, with the capability to encapsulate a wide range of hydrophilic or hydrophobic drugs, are usually made by the ring-opening co-polymerization of glycolide and lactide. One of the most notable characteristics of PLGA polymers as drug delivery systems is the possibility of adjusting the physicochemical properties like lactide/glycolide ratio in order to obtain the desired release profile. ${ }^{141}$ By following the solvent displacement technique, pelargonidin was encapsulated in PLGA to form nano pelargonidin which was found to protect alloxan-induced hyperglycemic L6 cells against mitochondrial dysfunction, oxidative stress, DNA damage, imbalance in glucose homeostasis in vitro and exhibited better protective effect than native pelargonidin with a $\sim 10$ fold reduced dose or showed a $\sim 10$-fold greater protective effect with an equivalent dose. ${ }^{141,142}$ Chitkara et al adopted the emulsion diffusion evaporation method to produce quercetin-loaded PLGA NPs for diabetes care with the aim to reduce dose and dosing frequency. In a pharmacokinetic study, the relative oral bioavailability of nano quercetin was increased by $523 \%$ as compared with quercetin suspension. The therapeutic effect on STZ-induced diabetic rats implied that the same dose of quercetin nanoformulation every 5 days was enough to produce a similar effect to the daily dose of quercetin suspension. ${ }^{78}$ Using the same preparation method as quercetin, Kozuka et $\mathrm{al}^{79}$ successfully fabricated $\gamma$ oryzanol-loaded PLGA NPs. Compared with regular $\gamma$ oryzanol, nano $\gamma$-oryzanol markedly ameliorated lipid and blood glucose metabolism in obese diabetic ob/ob mice with an unexpected amount (about 1000-fold lower dose). Even under the condition of treatment once every 2 weeks, such a prominent impact was also accomplishable. Marked efficacy differences between antidiabetic phytocompounds and their PLGA-based nanoformulations can be ascribed to the specialized uptake of NPs through payer's patches via M-Cells into lymphatic system and then directly into systemic circulation and thus avoiding first-pass metabolism. ${ }^{143}$ Furthermore, the PLGA matrix provided a barrier for phytocompounds to prevent them from enzymatic degradation in the GIT. $^{144}$

\section{PLA-Based NPs, PCL-Based NPs, and PVA-Based NPs}

PLA is often used with PGA to form PLGA. It is formed by the condensation polymerization of lactic acid, which is produced by the fermentation of sugars from carbohydrate sources like sugarcane, corn, or tapioca. ${ }^{145}$ PLA is a hydrophobic polymer because of the presence of $-\mathrm{CH}_{3}$ side groups. ${ }^{146}$ The stevioside was encapsulated into Pluronic-F-68-PLA through the nanoprecipitation method. ${ }^{147}$ The use of Pluronic F-68 surfactants in NPs synthesis can usually improve drug loading capacity, stability as well as cell-nanoparticle interaction. ${ }^{148,149}$ In this research, Pluronic-F-68 copolymer increased the encapsulation and bioavailability of stevioside and provided a longer sustained-release activity. The half release and complete release were respectively observed at $25 \pm 4 \mathrm{~h}$ and $200 \pm$ $10 \mathrm{~h}$ in vitro. ${ }^{147}$ Another compound, rebaudioside A, with one more extra glucose molecule in its chemical structure than stevioside, also possesses strong antidiabetic activity. To assess the effect of nano rebaudioside A and compare it with nano stevioside, the entirely same methodology as stevioside was applied to fabricate rebaudioside A PLA NPs. The antidiabetic effect of rebaudioside A NPs was claimed to be superior than that of stevioside NPs on account of achieved higher drug loading ability and similar in vitro release properties. ${ }^{150}$

PCL is a hydrophobic, semi-crystalline polymer. ${ }^{151} \mathrm{It}$ is achiral and has the ability to resist chemical hydrolysis, 
which improves the structural stability of polymeric chains in the nanoencapsulation. ${ }^{148}$ Kamaraj et al ${ }^{152}$ made 14 deoxy, 11, 12-didehydroandrographolide-loaded PCL NPs using the solvent evaporation technique. The results obtained from the study demonstrated that after nanoencapsulation, the glucose uptake effect in L6 myotubes in vitro was found to be improved because of its prolonged and sustained drug delivery. A biphasic pattern of drug release in vitro exerted an initial burst release at $24 \mathrm{~h}$ followed by a sustained release for up to 11 days.

PVA is a polymer with -OH hydrophilicity. It is produced by the radical polymerization of vinyl acetate and then followed with partial hydrolysis. Because of its unique properties like water solubility and multiple - $\mathrm{OH}$ groups for further chemical modification, it has been broadly used in drug delivery applications. ${ }^{153}$ Mishra et $\mathrm{al}^{80}$ completed the preparation of lutein PVA NPs by the precipitation method. The results showed that lutein PVA NPs at much lower doses caused a significant blood glucose-lowering effect along with prominent antihyperlipidemic and antioxidant effects compared with native lutein in non-insulindependent diabetic rats.

\section{Poly (Ethylene Glycol) (PEG) Surface Modification}

However, there are certain limitations of synthetic polymers such as opsonization by plasma proteins and subsequent recognition and clearance by mononuclear phagocyte system because of high surface hydrophobicity. ${ }^{154}$ These drawbacks can be overcome by PEGylation approach. PEG is a hydrophilic, nontoxic, blood-compatible polymer that is the most widely used material for the surface modification of NPs. ${ }^{155}$ PEG is applied to endow nanocarriers with a hydrophilic camouflage surface, which can provide several advantages in vivo applications, such as improving the hydrophilicity of synthetic polymer, minimizing immunogenicity and phagocytosis as related to rapid reticuloendothelial system, reducing intermolecular aggregation, and increasing aqueous solubility and stability in blood, eventually contributing to the prolonged circulation of NPs. ${ }^{156}$

El-Naggar et al $^{81}$ successfully developed curcuminloaded PLA-PEG NPs using the emulsion-diffusion evaporation technique. In this amphiphilic system, PLA represented the hydrophobic segment of the copolymer and PEG, the hydrophilic one. ${ }^{59}$ Hydrophobic curcumin was encapsulated into hydrophobic polymer's portion and stabilized by cationic surfactant (cetyltrimethylammonium bromide). The results validated the superiority of curcumin encapsulated into PLA-PEG NPs over both polymer NPs itself and free curcumin in elevating the level of plasma insulin, decreasing the level of plasma glucose, protecting the liver from inflammation, and ameliorating hepatic functioning in STZ-induced diabetic rats. ${ }^{81}$ Used PLGAPEG-COOH and PCL conjugate as carriers, novel polymeric NPs, which efficiently encapsulated fisetin, were fabricated by the nanoprecipitation technique. In the drug delivery system, PCL exhibited extraordinary capability to form blends with other polymers, which made it possible to design degradation kinetics and mechanical properties. $^{157}$ During the preparation of NPs, the PCL block could interact with PLGA to build a hydrophobic core, while the hydrophilic PEG-COOH chains could protrude from the particle surface to stabilize the core. ${ }^{158}$ In vitro release assays demonstrated that NPs could preserve and protect the release of fisetin under gastric-simulated conditions, along with controlling release in the intestinal medium. What's more, fisetin nanoformulation obtained an approximately 20 -fold higher $\alpha$-glucosidase inhibitory effect than commercial acarbose. ${ }^{157}$ Recent reports implied that PEG could cause an immunogenic response in mammals. However, the extent of this response elicited by the binding of anti-PEG antibodies is not clear. PEG remains the FDA approved polymer and is still the most extensively utilized polymeric coating of nanomedicines, either in industrial use or academic research. ${ }^{159}$

Despite synthetic polymers-based NPs with numerous benefits, there are still a couple of concerns about potential toxicity. Polymer toxicity can be a result of residual monomer in the prepared polymer product and/or physical interactions with biological homeostatic mechanisms, that is, gill oxygen transport. ${ }^{160}$ Besides, NPs also have certain other weaknesses including high manufacturing costs, unpredictable stability, and short shelf life. ${ }^{2,161}$

\section{Lipid-Based Nano Systems}

Lipid-based nano delivery systems are comprised of biocompatible/biodegradable lipid ingredients generally recognized as safe (GRAS), which have attracted considerable research attention over the last 15 years after the discovery that the oral bioavailability of poorly watersoluble drugs could be improved when they are coadministered with a diet rich in fat. ${ }^{162}$ Lipids are absorption enhancers because they can increase oral bioavailability of poorly water-soluble drugs in multitudinous ways like promoting dissolution as a micellar solution, acting as inhibitors of efflux transporters, and increasing 
the lymphatic uptake. ${ }^{162-164}$ Besides, the structural and chemical richness of lipids provides multiple possibilities to form delivery systems with different characteristics and contain various active compounds. ${ }^{165}$

\section{Nanoemulsions (NEs) and Self-Nanoemulsifying Drug Delivery Systems (SNEDDS) \\ NEs}

NEs are colloidal dispersions consisting of an oily phase, surfactant, and a water phase. ${ }^{166}$ It remains controversial in defined size values of NEs, with the upper limit fixed at $100 \mathrm{~nm}, 200 \mathrm{~nm}$,or $500 \mathrm{~nm}^{167}$ Generally, as oil droplets' size decreases, the energy density required to break down oil droplets increases, which signifies that high energy input is necessary to form NEs. Mechanical devices are often used, like ultrasonification, microfluidizers, and high-pressure homogenizers. ${ }^{168}$ NEs are drug delivery systems with the ability to entrap hydrophobic and hydrophilic molecules. ${ }^{166}$ It markedly enhanced the absorption of antidiabetic phytocompounds entrapped in NEs, which can be realized by the small particle size and high surface-tovolume ratio of NEs, the surfactant-induced membrane fluidity then permeability improvement, the stimulation of various lipid sensing mechanisms in GIT, and the initiation of intestinal lymphatic transport pathway. ${ }^{168-170}$

Bitter gourd seed oil was emulsified by the two-stage homogenization process for NEs preparation with a low surfactant to oil ratio (0.65). Bitter gourd seed oil NEs significantly ameliorated hyperglycemia and oxidative stressed state in alloxan-induced type 2 diabetic rats. Interestingly, compared with equivalent doses of bitter gourd seed oil conventional emulsion and $1 \%(\mathrm{w} / \mathrm{v})$ bitter gourd seed oil NEs, $0.5 \%(\mathrm{w} / \mathrm{v})$ bitter gourd seed oil NEs displayed maximum therapeutic efficiency possibly due to increased bioavailability. ${ }^{82}$ Further studies on pharmacokinetics are needed to conduct. Xu et $\mathrm{al}^{83}$ reported that NEs decreased the P-gp efflux of berberine by 2-fold and increased its permeability by 5.5 -fold in vitro Caco- 2 cells transport and in situ single-pass intestinal perfusion investigations. Compared with berberine control, NEs enhanced the oral bioavailability of berberine in vivo by $212.02 \%$ and reduced the blood glucose level of diabetic mice by 3 -fold. Moreover, the therapeutic effect of berberine NEs on diabetes was better than that of metformin. Cyclodextrin-based nanosponges, an innovative delivery system, are made up of hyper-cross-linked cyclodextrins connected in a three-dimensional network. ${ }^{171}$ They can surpass the limitations of native cyclodextrins. ${ }^{172}$
Superior properties are ascribed to their nanoporous, sponge-like structure, beneficial for encapsulation of complex lipophilic and hydrophilic phytocompounds. ${ }^{173}$ Nait Bachir et al synthesized two engineered NEs in order to enhance the bioactivity and stability of sage essential oil. ${ }^{84}$ The first one was stabilized by native $\beta$-cyclodextrin employing physical method and the second one was stabilized by $\beta$-cyclodextrin nanosponges using naphthalene dicarboxylic acid as a cross-linking agent and employing polycondensation method. The experiment results revealed the stability of the latter was higher than that of the former. The antidiabetic activity in vivo of NEs stabilized by $\beta$ cyclodextrin nanosponges performed better curative efficacy than that of NEs stabilized by natural $\beta$-cyclodextrin and free sage essential oil. ${ }^{84}$ Hatanaka et al prepared three NEs of $\alpha$-tocopherol at different loading amounts $(10 \%$, $30 \%$, and $50 \%$ ) via the mechanochemical method using a homomixer and microfluidizer. By comparison with the control mixture of oil and $\alpha$-tocopherol, $10 \% \alpha$-tocopherol -loaded NEs exhibited a 2.6-fold increased bioavailability in vivo and a more significant antioxidative effect on several organs, especially the liver, in STZ-induced diabetic rats. However, when the content of $\alpha$-tocopherol of NEs was $30 \%$ or higher, severe droplet aggregation occurred during long-time storage. ${ }^{85}$ The main restriction that reduces the wide application of NEs is stability. ${ }^{174}$ NEs are thermodynamically unstable and kinetically stable systems. ${ }^{175}$ In other words, if NEs are given sufficient time, phase separation eventually occurs. Ostwald ripening is the main destabilization mechanism of NEs. ${ }^{176}$ It was reported that during storage and applications, the stability of NEs could be maintained against environmental factors including $\mathrm{pH}$ and temperature by controlling size, surfactant, and oil concentrations. ${ }^{177}$

\section{SNEDDS}

In contrast to NEs, SNEDDS do not incorporate any water, so they are much more chemically as well as physically stable, and therefore can be easily stored for a longer time. ${ }^{178}$ Besides, free energy required to produce SNEDDS is very low, and the formulation is thermodynamically spontaneous. ${ }^{179}$ SNEDDS (pre-emulsion concentrates) are anhydrous isotropic mixtures of oil, drug, surfactant, and/or co-surfactant. Such systems are diluted by aqueous phase (gastrointestinal fluids) in vivo, and then under gentle agitation provided by the digestive motility of the intestine and stomach, they can form fine oil-in-water NEs, providing a large interfacial surface area for 
improving drug absorption. So, one of the most crucial features of SNEDDS is the change that occurs when the system is diluted by body fluids after administration. ${ }^{162,180,181}$ Hence, it is crucial to identify efficient self-emulsification regions and decide on the most suitable concentrations of surfactant, cosurfactant, and oil for the formulation of SNEDDS with good stability. Garg et $\mathrm{al}^{87}$ prepared SNEDDS of polypeptide-k and curcumin for better antidiabetic efficacy in STZ-induced diabetic rats. A pseudo-ternary phase diagram was constructed through oil (labrafil M 1944 CS), surfactant (tween-80), cosurfactant (transcutol P) to select the efficient self-emulsification region. Box-Behnken design was utilized to optimize the liquid formulation based on the results of zeta potential, percentage drug loading, polydispersity index, and mean droplet size. Under the condition of variation in $\mathrm{pH}$, dilution, and temperature, the absence of phase separation and drug precipitation suggested that the optimized formulation was stable. The rate of emulsification is a crucial index for the evaluation of the efficiency of emulsification. The self-emulsification time of optimal formula resveratrol SNEDDS (propylene glycol, tween 80, and olive oil in the ratio 533.3:266.7:200) was only $27 \pm 0.8 \mathrm{~s}$ without precipitation in vitro. Ten milligram/kilogram resveratrol nanoformulation displayed significant hypolipidemic and hypoglycemic effects on STZ and glucose induced-diabetic rats, similar to the high dose $(20 \mathrm{mg} / \mathrm{kg})$ of free resveratrol. ${ }^{88}$ In another study, the relative oral bioavailability in vivo of transcinnamic acid SNEDDS (10\% PEG 400, 30\% isopropyl myristate, and 60\% Kolliphor EL) was approximately $246 \%$ as compared with trans-cinnamic acid suspension, indicating that SNEDDS have a remarkable capability to improve bioavailability. ${ }^{89}$ These phenomena can be attributed to multi-concerted mechanisms like reduced intraenterocyte metabolism through cytochrome P450 enzymes, decreased P-gp efflux activity, and bypassed hepatic first-pass metabolism through lymphatic absorption. ${ }^{182}$ SNEDDS of trans-cinnamic acid enhanced the antidiabetic efficacy of trans-cinnamic acid in alloxaninduced diabetic rats, which could be comparable to that of metformin. ${ }^{89}$ SNEDDS are related with many merits, but they still have some defects. Characterization- and formulation-associated issues include the correlation of in vitro model with in vivo studies, the usage of a high amount of surfactant, the precipitation of drug in vivo, the oxidation potential of lipid components, the difficulty of low encapsulation, etc. ${ }^{183}$ Nowadays, research is moving towards some novel applications of SNEDDS to make up for their shortcomings, such as self-double emulsions (w/o/ w), solid SNEDDS, controlled release SNEDDS, supersaturated SNEDDS, targeted SNEDDS. ${ }^{175,184,185}$ For example, solid SNEDDS are more stable and amenable to compress into tablets as compared to their liquid counterparts. $^{186}$ Garg et al ${ }^{86}$ solidified liquid SNEDDS of polypeptide-k using Aerosil 200 as hydrophobic carrier through the spray drying technique. The biochemical, hematological, and histopathological results of STZinduced diabetic rats revealed better antidiabetic potential of polypeptide-k loaded in SNEDDS than that of naive form.

\section{Solid Lipid NPs (SLNs) and Nanostructured Lipid Carriers (NLCs)}

Lipid-based NPs possess an inner solid lipid phase. According to their internal structure, lipid-based NPs are divided into solid lipid NPs (SLNs) and nanostructured lipid carriers (NLCs). ${ }^{187}$ As the first generation of lipidbased NPs, SLNs are only composed of solid lipids, whereas NLCs, as the upgrade of SLNs, are composed of a mixture of liquid and solid lipids, but the solid lipid is in a relatively high amount to fabricate nanoparticles. This solid matrix realizes the controlled release of enclosed either lipophilic or hydrophilic molecules, protects them from degradation, and increases the long-time stability of the system. ${ }^{188}$ Numerous methods have been reported for the preparation of lipid NPs like hot and cold highpressure homogenization, microemulsion-based technique, solvent emulsification/evaporation, solvent diffusion method, etc. ${ }^{163}$ Probably the most vital reasons for lipid NPs as a suitable alternative to previous polymeric NPs, are low toxicity potential and the ease of large-scale production. $^{189}$

\section{SLNs}

Because myricitrin is susceptible to high temperature, the cold homogenization method has been employed to prepare myricitrin SLNs. SLNs of myricitrin exhibited antioxidant, antidiabetic, and antiapoptotic activities in STZnicotinamide-induced diabetes in mice and hyperglycemic myotubes. ${ }^{90}$ In another study, a solvent injection method was utilized to develop the resveratrol SLNs. Compared with pure resveratrol, oral administration of resveratrol SLNs to rats with T2DM showed better hypoglycemic effects and more significantly reduced the expression of SNARE proteins associated with insulin resistance in 
muscle and adipose tissue. ${ }^{91}$ Xue et al ${ }^{92}$ prepared berberine SLNs using their patented method, the solvent diffusion method (No 201210495674.4, People's Republic of China patent). Oral pharmacokinetic studies in vivo showed $\mathrm{AUC}_{0 \sim \mathrm{t}}, \mathrm{C}_{\max }, \mathrm{t}_{1 / 2}$, and $\mathrm{VRT}_{0 \sim \mathrm{t}}$ of berberine SLNs were $113.57 \pm 72.93 \mu \mathrm{g} \cdot \mathrm{h} / \mathrm{L}, 44.65 \pm 4.77 \mu \mathrm{g} / \mathrm{L}$, $11.50 \pm 10.78 \mathrm{~h}$, and $42.58 \pm 21.82 \mathrm{~h}$, respectively, in contrast to $56.48 \pm 29.61 \mu \mathrm{g} \cdot \mathrm{h} / \mathrm{L}, 11.06 \pm 6.24 \mu \mathrm{g} / \mathrm{L}$, $9.228 \pm 5.13 \mathrm{~h}$, and $23.40 \pm 13.92 \mathrm{~h}$ of pure berberine. The above results indicated that nanoformulations could promote absorption, possess a slow-release character, and reduce fluctuations in drug concentrations. Consequently, berberine SLNs exerted more powerful effectiveness than an equivalent dose of berberine in $\mathrm{db} / \mathrm{db}$ mice, especially for the effect on improving insulin sensitivity and glucose tolerance. After further research, Xue et $\mathrm{al}^{93}$ found that the drug concentration of berberine SLNs group in the liver was approximately 2 -fold higher than that of berberine group. The maximum drug concentration in the liver was 20 -fold higher than that in the blood after oral administration of berberine SLNs, suggesting a predominant accumulation of berberine SLNs in the liver. However, the capability of SLNs to transform crystalline phases-lowenergetic form results in an increased degree of order which decreases the imperfections in the crystal lattice followed by drug expulsion phenomena and low encapsulation efficiency (Figure 2). ${ }^{71,190}$ For example, the encapsulation efficiency of the discussed SLNs of myricitrin, ${ }^{90}$ resveratrol, ${ }^{91}$ berberine $^{92,93}$ is $56.2 \%, 79.9 \%, 58 \%$, respectively.

\section{NLCs}

NLCs are designed to triumph over SLNs shortcomings. NLCs are also maintained in solid state at room and body temperature. ${ }^{165}$ However, instead of only a solid lipid, a liquid lipid or a mixture of liquid lipids are used to replace the part of a solid lipid, leading to a less ordered lipid matrix-imperfect crystal lattice (Figure 2) which contributes to increased loading efficiencies, enhanced stability along with the prevention of drug expulsion during storage, ${ }^{190,191}$ as illustrated by the following studies.

Two lipid-based nanocarriers for oral delivery of silymarin were prepared through the method of emulsion/ evaporation/solidifying. ${ }^{94,95}$ The first one was produced with lauroglycol 90 as liquid lipid, cetyl palmitate as solid lipid, and Brij S20 as surfactant, ${ }^{94}$ the second one with capryol 90 as liquid lipid, stearic acid as solid lipid, and Brij S20 as surfactant. ${ }^{95}$ Both encapsulation efficiency was more than $92 \%$ with excellent chemical and physical stability. In vitro release studies showed that NLCs may improve the passive permeation of silymarin via the Caco2 cell layer. In vivo, both silymarin-loaded NLCs exhibited a more significant down-regulation of triglyceride and blood glucose levels compared with native silymarin. Besides, both nanoformulations performed a remarkable antihyperalgesic activity on STZ-induced neuropathy. However, the second nanoformulation showed more pronounced and longer lasting therapeutic effects. ${ }^{94,95}$ Similarly, in another study, baicalin NLCs were formed by the hot melting high-pressure homogenization method using miglyol as liquid lipid and precirol as solid lipid. The results suggested that baicalin NLCs had a better capability to retain drugs and possessed relatively good physical stability. To be specific, during 1 month of storage at $4^{\circ} \mathrm{C}$, aggregation and gelation were not found by visual observation and no significant change of zeta potential, particle size, and polydispersity index was discovered by data analysis, indicating relative good physical stability of baicalin NLCs; the average encapsulation efficiency of freshly prepared baicalin NLCs was $85.29 \pm 3.42 \%$, indicating their better ability to retain drugs. Compared with pure baicalin, baicalin NLCs had better hypoglycemic and hypolipidemic effects in vivo. ${ }^{96}$ In the past few years, at the academic level, the potential of NLCs as drug delivery systems has been broadly researched. However, to the best of our knowledge, no NLCs for therapeutical use have obtained the regulatory approval or even have reached the clinical study stage until now. ${ }^{191}$

\section{Vesicular Systems}

Vesicles are colloidal systems with a size of less than a micrometer. ${ }^{192}$ Vesicular delivery systems are composed of an aqueous core generally surrounded by one or more lipidic bilayers. ${ }^{193}$ The hydrophilic agents are enclosed in the inner aqueous core, while lipophilic drugs in the lipid bilayer. ${ }^{194}$ The agents encapsulated in lipid vesicles can easily cross the cell membrane, which alters the rate and extent of the absorption of agents and their disposition. ${ }^{195}$ Vesicular delivery systems of antidiabetic phytocompounds that have been studied so far are discussed below.

\section{Liposomes}

Phospholipids are the major component of all biological membranes. ${ }^{196}$ Liposomes are phospholipid bilayer vesicles. It has been over 50 years that liposomes explored in pharmaceutical research as drug delivery systems. ${ }^{197}$ Due to 
the use of phospholipids, liposomes possess a biofilm similar structure and exhibit excellent biocompatibility. ${ }^{198,199}$ More than 40 liposomes loaded with drugs are under different clinical research stages or have been successfully marketed. $^{199}$

Amjadi et al used the ultrasonic-mechanical method for the fabrication of betanin liposomes. In vitro release studies, betanin-loaded liposomes exhibited a relatively favorable sustained release profile in simulated intestinal and gastric fluids. Liposomal encapsulation improved the physicochemical stability of betanin during in vitro digestion and more effectively regulated hyperlipidemia, hyperglycemia, and oxidative stress than free betanin in STZ-induced rats. ${ }^{97}$ Yucel et al prepared nanoliposomal formulations containing resveratrol using the dry film hydration method. It was concluded that nanoformulation significantly decreased high glucose levels along with increasing insulin levels in glucose and STZ-induced diabetic $\beta$-TC 3 cells, and exerted prolonged antioxidant activity for $24 \mathrm{~h}$ as compared with resveratrol solution. ${ }^{200}$ However, the therapeutical use of liposomes exists some restrictions, predominantly their high formulation cost and poor stability under harsh conditions, typically exposed to the GIT. Some studies have been reported on the use of cochleates as an alternative platform to liposomes in order to surpass these limitations. ${ }^{201}$

\section{Nanocochleates}

Nanocochleates are stable phospholipid precipitates derived from the physical interaction of divalent cation with anionic lipid vesicles, ${ }^{202}$ generally phosphatidylserine and calcium. ${ }^{203}$ Nanocochleates have cylindrical (cigarlike) microstructures made up of solid, lipid bilayer sheet which was rolled up in a spiral or in stacked sheets to minimize their interaction with water, consequently, nanocochleates with no or little internal aqueous space. ${ }^{203,204}$ This unique structure provides protection for the encapsulated drugs from biodegradation, even if they are exposed to hazardous environmental conditions in the GIT. ${ }^{205}$ Yucel et $\mathrm{al}^{206}$ developed resveratrol-loaded nanocochleates by the trapping method and assessed their therapeutic efficiency in diabetic pancreatic $\beta$ TC cell line in vitro. Compared with native resveratrol, the lower dose of nanocochleates loaded with resveratrol better improved the decreased insulin levels rendered with glucose and STZ, markedly reduced the increased glucose levels, and also exhibited prolonged antioxidant activity for $24 \mathrm{~h}$. However, self-aggregation, which usually happens during production and storage, is currently the major obstacle hindering the development of efficient cochleate-based drug delivery systems. ${ }^{207}$

\section{Niosomes}

Niosomes are such hydrated vesicular systems mainly consisting of cholesterol along with nonionic surfactants. Niosomes can keep stable over a longer period of time in different conditions and require less cost of production, so break through major restrictions of liposomes. ${ }^{208}$ Sharma et $\mathrm{al}^{209}$ prepared lycopene-loaded niosomes by developing a novel method called adsorption-hydration technique. The release mechanism of lycopene was Fickian type and followed zero-order release kinetics in the first $10 \mathrm{~h}$, after that the regression equation best matched KorsmeyerPeppas model. Thus, the lycopene release from niosomes in vitro was sustained and prolonged profile, which was beneficial to reduce dosing frequency. Antidiabetic studies in vivo showed lycopene-loaded niosomes had an activity similar to a standard antidiabetic drug, glibenclamide. ${ }^{98}$ Similarly, embelin-loaded niosomes, produced by the thinfilm hydration process, displayed a hypoglycemic effect in vivo which was comparable to another standard antidiabetic agent, repaglinide. Moreover, lipid peroxidation decreased and glutathione (GSH), catalase (CAT), and superoxide dismutase (SOD) increased significantly, which verified the antioxidant efficacy of the nanoformulation. ${ }^{99}$ In another study of Singhal et al, ${ }^{100}$ researchers used the thin-film hydration technique to prepare gymnemic acid-loaded niosomes which revealed antioxidant, antihyperglycemic, antihyperlipidemic, and antiglycation (AGEs) effects and eventually, exerted a protective action in STZ-nicotinamide-induced diabetic nephropathy in Wistar rats.

\section{Phytosomes}

Phytosomes, also known as phytophospholipid complexes, are prepared by interactions between active phytocompounds and the polar part of phospholipids. ${ }^{210,211}$ The biggest difference between liposomes and phytosomes is that, in liposomes, the active phytocompound is distributed in lipid layers of the membrane or in the medium containing a cavity, ${ }^{211}$ whereas, in phytosomes, it is an integral part of the membrane, which gives the greater stability and better bioavailability because of the chemical links between active phytocompounds and phospholipid molecules (Figure 2). ${ }^{213,214} \mathrm{Yu}$ et al ${ }^{101}$ prepared phytosomes loaded with berberine phospholipid complex using the 
rapid solvent evaporation method followed by selfassembly technique. In vivo studies, this nanoformulation could produce a 3-fold enhanced oral bioavailability of berberine. More importantly, the antidiabetic efficacy was improved remarkably in $\mathrm{db} / \mathrm{db}$ mice by ameliorating hyperlipidemia and lowering fasting glucose levels. Besides, the types of phospholipid matrix applied in the preparation of phytosomes influenced their performance. For instance, compared with pure chrysin and chrysin prepared with soya phosphatidylcholine, chrysin prepared with egg phospholipid exhibited a greater glucose uptake promoting effect in $\mathrm{C} 2 \mathrm{C} 12$ muscle cells through upregulating gene expression of PPAR $\gamma$ and GLUT4. ${ }^{214}$

\section{Micelles}

Micelles have been extensively studied as nanocarriers for hydrophobic drugs with core/shell design. They commonly have a particle size within $5-50 \mathrm{~nm}$ range. ${ }^{215}$ Micelles are made by the self-assembly of amphiphilic molecules in aqueous media above the critical micelle concentration (CMC). ${ }^{216}$ The hydrophobic portion of amphiphilic molecules constitutes the core of the micelle, which serves as a reservoir and protects the agent, while the hydrophilic portion constitutes the micelles' shell, which confers steric stability and aqueous solubility to the micellar structure. $^{217,218}$

The transplantation of islet $\beta$-cells is an efficient therapy for type 1 and 2 diabetes. However, the isolated islets are under hypoxic conditions and then undergo the apoptotic process. Therefore, it is necessary to protect islets against hypoxia for enhancing the efficacy of islet transplantation. A peptide micelle-mediated curcumin delivery system was demonstrated to be effective for islet $\beta$-cells protection in the process of transplantation in vitro. This delivery system was developed by Han et al through an oil-in-water $(\mathrm{O} / \mathrm{W})$ emulsion/solvent evaporation method. In addition, the peptides consisted of a 3-arginine hydrophilic stretch and a 6-valine hydrophobic stretch. ${ }^{219}$ Zhang et al used the dialysis method to fabricate an amentoflavone-loaded micelle system composed of amphiphilic copolymer ( $\mathrm{N}$-vinyl pyrrolidone and maleic acid guerbet alcohol monoester). Owing to the micelle formation, the oral bioavailability of amentoflavone was increased by nearly 3.2 times in vivo. The antidiabetic effect of amentoflavone nanoformulation is comparable to that of metformin in insulin-resistant diabetic KKAy mice. ${ }^{102}$ Soluplus ${ }^{\circledR}$ is one such commercially triblock copolymer composed of PCL-Polyvinyl acetate (PVAc)-PEG units with the capability to enhance the solubility and bioavailability of poorly water-soluble drugs. ${ }^{220}$ Singh et al ${ }^{103}$ prepared quercetin-loaded soluplus ${ }^{\circledR} /$ poloxamer 407 micelles by the cosolvent evaporation method. In this system, poloxamer 407 was used as a surfactant in order to enhance the solubilization of quercetin and increase the stability of nanomicelles. In vivo pharmacokinetic studies, the relative oral bioavailability of quercetin nanoformulation was $1676 \%$ as compared to pure drug suspension. Moreover, quercetin nanoformulation showed significantly lower glucose levels, higher catalase and SOD levels in STZ-induced diabetic rats. Pluronics is another type of triblock copolymers with a central hydrophobic poly (propylene oxide) (PPO) chain and two hydrophilic poly (ethylene oxide) (PEO) on each side, arranged in PEO-PPO-PEO structure. ${ }^{221}$ Pluronic micelles are capable to increase the stability and solubility of incorporated drugs and improve their pharmacokinetics and biodistribution. $^{222}$ El-Far et al developed silymarinloaded pluronic nanomicelles ${ }^{104}$ and curcumin-loaded pluronic nanomicelles ${ }^{105}$ using the nanoprecipitation technique. Nanoformulations were found to significantly improve the antihyperlipidemic, antioxidant, and antihyperglycemic properties in STZ-induced diabetic rats when compared with their native candidates. As we discussed, both synthetic and inartificial polymers have their own merits and defects. Combinations of these polymers could make the best use of the advantages and bypass the disadvantages. Using alginate, chitosan, maltodextrin, pluronic P123, pluronic F127, and tween 80 , Akbar et al ${ }^{106}$ developed curcumin-loaded mixed polymeric micelles by the thin-film hydration method. The achieved results showed that the antidiabetic activity of curcumin-loaded mixed polymeric micelles was comparable to that of metformin in bisphenol A-induced diabetics rats. Besides, curcumin-loaded mixed polymeric micelles administered topically on the surface of wound performed superior wound healing potential (fast wound closure) with the reduction of scar formation in vivo. However, the primary challenge faced by micelles is that micelles tend to disintegrate and cannot keep entrapped drugs stabilized when they are diluted below the CMC. This phenomenon typically occurs when the drug/micelle formulation is infused into body and will lead to severely decrease drugs' bioavailability and deteriorate therapeutic performance. ${ }^{223}$

\section{Inorganic Nanocarriers}

Inorganic materials have been employed to explore nanocarriers with controlled morphology and size. ${ }^{224}$ Recent breakthroughs on the surface functionalization and 
structural control of inorganic nanocarriers have brought more possibilities for drug delivery. ${ }^{225}$

\section{Metallic NPs}

Metallic NPs such as selenium, ${ }^{226,227}$ gold, ${ }^{228}$ silver, ${ }^{229,230}$ and zinc oxide NPs ${ }^{107,231}$ appear very promising for the treatment of T2DM. ${ }^{232}$ However, metallic NPs are synthesized by physical and chemical methods with many shortcomings, including high energy consumption, the use of toxic solvents, and the generation of hazardous byproducts. $^{233}$ The biosynthesis of metallic NPs through medicinal plants has obtained widespread attention as a proper alternative to hazardous chemical synthetic technique. $^{234}$ Antidiabetic phytocompounds act as reducing and stabilizing agents during the synthesis of metallic NPs. Currently, there have been many papers reporting the use of antidiabetic phytocompounds as stabilizing and reducing agents to synthesize metallic NPs, such as gymnemic acid gold NPs, ${ }^{235}$ vicenin gold NPs, ${ }^{236}$ escin gold NPs, ${ }^{237}$ docosahexaenoic acid zinc oxide NPs, ${ }^{107}$ and guavanoic acid gold NPs. ${ }^{238}$ In these studies, all of them showed good antidiabetic effects in vitro or/and in vivo. Besides, phytocompounds with antidiabetic effects can enhance the diabetic efficacy of metal NPs. For instance, Catathelasma ventricosum polysaccharides SeNPs exhibited significantly higher antidiabetic effects than other selenium preparations like SeNPs, selenocysteine, sodium selenite. ${ }^{108}$ On the base of berberine-loaded NLCs, Yin et $\mathrm{al}^{109}$ used an in-situ reduction technique to fabricate berberine-loaded SeNLCs, as $\mathrm{Se}^{4+}$ was reduced to $\mathrm{Se}$ which precipitated on the surface of NPs. In vivo studies reported berberine SeNLCs yielded the highest $\mathrm{C}_{\max }$ and $\mathrm{AUC}_{0-\mathrm{t}}$, up to $172.88 \mathrm{ng} / \mathrm{mL}$ and $1,107.80 \mathrm{ng} \cdot \mathrm{h} / \mathrm{mL}$, when compared with berberine solution $\left(\mathrm{C}_{\max }=45.06 \mathrm{ng} / \mathrm{mL}\right.$, $\left.\mathrm{AUC}_{0-\mathrm{t}}=173.74 \mathrm{ng} \cdot \mathrm{h} / \mathrm{mL}\right)$ and berberine NLCs $\left(\mathrm{C}_{\max }\right.$ $=148.21 \mathrm{ng} / \mathrm{mL}, \mathrm{AUC}_{0-\mathrm{t}}=689.54 \mathrm{ng} \cdot \mathrm{h} / \mathrm{mL}$ ). Accordingly, the hypoglycemic activity of berberine SeNLCs was also significantly superior to that of berberine solution and berberine NLCs. It turned out that Se coating, plus the synergy of selenium, was basically responsible for increased oral bioavailability and enhanced hypoglycemic activity in vivo.

\section{Carbon Nanotubes}

Carbon nanotubes are tiny tubes approximately 10,000 times thinner than a human hair. They consist of rolledup sheets of carbon hexagons. ${ }^{239}$ Either by noncovalent interactions or covalent attachment, drugs can be loaded within the interior core or onto the surface of carbon nanotubes. $^{240}$ In comparison with spherical NPs, carbon nanotubes' needlelike shape gives them superior flow dynamics and enhanced capacity to penetrate cellular membranes. $^{241}$ Ilie et $\mathrm{al}^{242}$ firstly prepared nanotubes with oxidation properties using 1:3 (v/v) concentrated nitric acid and sulfuric acid, which gave them stability and hydrophilicity in aqueous systems because of the formation of $-\mathrm{OH}$ and $-\mathrm{COOH}$ groups on the lateral sides of or at the end of the tubes. And then, Ilie et $\mathrm{al}^{242}$ covalently conjugated nicotinamide onto the surfaces of oxidized multiwalled carbon nanotubes. In vitro study, 1.4E7 cells administrated with nicotinamide-functionalized multiwalled carbon nanotubes better regulated insulin secretion and increased insulin production as compared with nicotinamide or multiwalled carbon nanotubes.

\section{Mesoporous Silica NPs (MSNs)}

Based on unique intrinsic properties of MSNs such as large pore volume, high surface area, facile functionalization of surface, uniform and tunable pore size, and stable framework, they have been utilized extensively as drug carriers. $^{225,243}$ It is widely agreed in published literature that endocytosis is a common mechanism for the translocation of MSNs. ${ }^{243}$ Huang et al ${ }^{110}$ designed the surface functionalization of MSNs with amine groups to act as reservoirs for efficient immobilization of phytocompounds into pores for antidiabetic therapies. The results revealed that 16-Hydroxycleroda-3,13-Dine-16,15-Olid incorporated into MSNs caused a reduction of DPP4 activity in a dose- and time-dependent fashion in vitro and simultaneously possessed less adverse effects and reliable efficacy in down-regulation of hyperglycemia in diet-induced diabetic mice.

Although inorganic NPs can be metabolized by the kidney after their degradation into small-sized fragments, ${ }^{244}$ most inorganic nanomaterials still have high bioaccumulation risks. ${ }^{245}$ Moreover, the generated ions, especially heavy metals, may lead to toxicity or damage to the related organs during the excretion. ${ }^{244}$ Therefore, it is essential to systematically study the toxicity of these nanomaterials to different organs in the process of metabolism. ${ }^{246}$

\section{Nanosuspensions}

Drug nanocrystals are nanosized drug particles often formed as nanosuspensions, namely submicron dispersions in liquid media where surfactants and/or polymers act as 
stabilizers. Although, without any carriers, nanosuspensions are an excellent delivery platform for poorly watersoluble drugs. ${ }^{247}$ Reducing the drug size to nanoscale usually causes a significant increase in solubility and dissolution rate along with a distinct improvement in oral bioavailability. ${ }^{248}$ Up to now, several studies have been reported that nanosuspensions enhanced the therapeutic effects of antidiabetic phytocompounds on diabetes, such as ursolic acid, ${ }^{113}$ berberine, ${ }^{114}$ curcumin, ${ }^{111}$ gymnemic acids. ${ }^{115}$ Chen et $\mathrm{al}^{249}$ prepared Fructus Mori polysaccharides with spherical particles by the antisolvent precipitation method. According to the research results, the smaller the particle, the higher the bioavailability. We can deduce that the smaller size after spheroidization is able to be beneficial for the improved bioavailability. In comparison with the corresponding native polysaccharide, the spheroidization improved the hypoglycemic activity and antioxidant ability in vitro. Zhao et $\mathrm{al}^{116}$ developed betulin nanocrystallization by the antisolvent precipitation technique. The results exhibited that nano betulin possessed the same chemical structure as raw betulin, but have smaller crystal size and lower crystallinity. The solubility and dissolution rate of nano betulin were, respectively, 1.54 and 3.12 times of raw drug. Compared with raw betulin, betulin nanosuspensions showed a 1.21-fold increased bioavailability in vivo and an excellent hypoglycemic effect in STZ-induced diabetic rats. However, instability is the most disadvantage of nanosuspensions and restricts their application to pharmaceutical industry. ${ }^{250}$ Stabilizers are crucial to prevent the aggregation of high energy nanosuspensions. Nonetheless, a suitable stabilizer is often selected by a trial and error method. ${ }^{251}$ Meanwhile, the potential raised toxicity concerns if the stabilizers are used in large quantities for a long term. ${ }^{252}$

\section{Conclusion}

As antidiabetic agents, phytocompounds are potential candidates with abundant sources, significant curative effects, and low side-effects. Generally, there are four hypoglycemic mechanisms of phytocompounds, including reduction of carbohydrate decomposition and glucose absorption, promotion of glucose uptake and metabolism, improvement of insulin action and sensitivity, and antioxidant and antiinflammatory actions. However, conventional oral administration of antidiabetic phytocompounds has some inherent defects. Oral nano drug delivery systems for phytocompounds to treat T2DM not only maintain the advantages of oral administration but also overcome the shortcomings of conventional oral drug delivery.

In this review, we discussed phytocompounds-based oral nano delivery systems for T2DM treatment, including polymeric NPs, lipid-based nanosystems, vesicular systems, micelles, inorganic nanocarriers, and nanosuspensions. As observed in studies, oral nano drug delivery systems for T2DM treatment have the following advantages: 1) phytocompounds encapsulated into nano delivery systems can improve the stability of the former and protect them from enzymatic and/or chemical degradation in GIT. 2) nano delivery systems act at the molecular level to increase the cellular drug uptake or block drug efflux mechanisms like P-glycoprotein (P-gp) pump, which further improves the pharmacokinetic and pharmacodynamic profile of antidiabetic molecules. ${ }^{2}$ 3) oral drug bioavailability can be significantly limited by first-pass hepatic metabolism. Intestinal lymphatic drug transport is regarded as the best for improving oral drug delivery through bypassing first-pass metabolism. Nano delivery systems can be transferred into the lymph, arrive at lymphatic system through $\mathrm{M}$ cells, and increase the subsequent release of drugs in systemic circulation. ${ }^{253} 4$ ) tailored engineering of nanocarriers fulfills controlling drug release, preventing opsonization, and targeting drug delivery. ${ }^{2}$ Due to the above advantages, phytocompounds have clearly shown better antidiabetic efficacy in oral nano drug delivery systems with increased bioavailability, decreased toxicity, targeted specific site, and reduced dose and dosing frequency.

However, there are still some deficiencies in the existing research. On the one hand, it is worth noting that a control group administered with non-loaded carrier is not conducted in the vast majority of works so that the drug-independent effect of the carrier cannot be ignored. Rho et al ${ }^{254}$ reported that empty self-assembled hyaluronic acid NPs without any drug could be used as a therapeutic agent for T2DM treatment. On the other hand, most of those materials used for the preparation of nano delivery systems are usually obtained from inorganic matter or synthetic polymers through a rather complex and tedious synthesis process, which may inevitably result in potential toxicity. Even if materials from natural sources are employed as nanocarriers, organic chemicals may be introduced into the process due to the requirement for the preparation. Security is a prime concern. However, the majority of published data come from cellular and animal models but not a clinical study. 
Since toxicological research in animals has limitations, clinical trials are ultimately required. There are few clinical trials on potential antidiabetic nano phytocompounds, only curcumin nanomicelle, ${ }^{255}$ curcumin nanocapsules. $^{256}$ Despite few severe adverse effects were reported during the treatment, long-term human toxicology research is still lacking. The FDA recently issued guidance to help promote the safe development of nanotechnology-based products for clinical use. ${ }^{257}$ More clinical research is worth conducting.

Above all, oral nano drug delivery systems for T2DM treatment are an available administration strategy for antidiabetic phytocompounds. This review could provide researchers with promising antidiabetic phytocompounds and excellent oral delivery systems to explore more therapeutic possibilities. With the extensive development of the pharmacological activity research of antidiabetic phytocompounds and the continuous progress of material science and technology, more and more excellent oral nano phytocompounds will be employed in clinical pharmaceutical intervention for T2DM treatment.

\section{Acknowledgments}

The authors would like to express their gratitude to Chuanhong Luo, Jiaying Long for proof reading the article.

\section{Disclosure}

Xin Nie, Zhejie Chen are co-first authors. The authors report no conflicts of interest in this work.

\section{References}

1. Fangueiro JF, Silva AM, Garcia ML, Souto EB. Current nanotechnology approaches for the treatment and management of diabetic retinopathy. Eur J Pharm Biopharm. 2015;95(Pt B):307-322. doi:10.1016/j.ejpb.2014.12.023

2. Uppal S, Italiya KS, Chitkara D, Mittal A. Nanoparticulate-based drug delivery systems for small molecule anti-diabetic drugs: an emerging paradigm for effective therapy. Acta Biomaterialia. 2018;81:20-42. doi:10.1016/j.actbio.2018.09.049

3. Thomas CC, Philipson LH. Update on diabetes classification. Med Clin North Am. 2015;99(1):1-16.

4. Ran Q, Wang J, Wang L, Zeng HR, Yang XB, Huang QW. Rhizoma coptidis as a Potential Treatment Agent for Type 2 Diabetes Mellitus and the Underlying Mechanisms: A Review. Front Pharmacol. 2019;10:805.

5. Sun Z, Sun X, Li J, et al. Using probiotics for type 2 diabetes mellitus intervention: advances, questions, and potential. Crit Rev Food Sci Nutr. 2020;60(4):670-683.

6. Manukumar HM, Shiva Kumar J, Chandrasekhar B, Raghava S, Umesha S. Evidences for diabetes and insulin mimetic activity of medicinal plants: present status and future prospects. Crit Rev Food Sci Nutr. 2017;57(12):2712-2729.
7. Rios JL, Francini F, Schinella GR. Natural Products for the Treatment of Type 2 Diabetes Mellitus. Planta Med. 2015;81 (12-13):975-994.

8. Choudhury H, Pandey M, Hua CK, et al. An update on natural compounds in the remedy of diabetes mellitus: A systematic review. J Tradit Complement Med. 2018;8(3):361-376.

9. Habtemariam S. The Quest to Enhance the Efficacy of Berberine for Type-2 Diabetes and Associated Diseases: physicochemical Modification Approaches. Biomedicines. 2020;8:4.

10. Adisakwattana S. Cinnamic Acid and Its Derivatives: mechanisms for Prevention and Management of Diabetes and Its Complications. Nutrients. 2017;9(2):2. doi:10.3390/nu9020163

11. Inzucchi SE, Bergenstal RM, Buse JB, et al. Management of Hyperglycemia in Type 2 Diabetes, 2015: A Patient-Centered Approach: update to a Position Statement of the American Diabetes Association and the European Association for the Study of Diabetes. Diabetes Care. 2015;38(1):140-149. doi:10.2337/ dc14-2441

12. Rubino F, Schauer PR, Kaplan LM, Cummings DE. Metabolic surgery to treat type 2 diabetes: clinical outcomes and mechanisms of action. Annu Rev Med. 2010;61(1):393-411. doi:10.1146/ annurev.med.051308.105148

13. Yanai H, Adachi H, Katsuyama H, Moriyama S, Hamasaki H, Sako A. Causative anti-diabetic drugs and the underlying clinical factors for hypoglycemia in patients with diabetes. World $J$ Diabetes. 2015;6(1):30-36.

14. Salehi B, Ata A, Vak N, et al. Antidiabetic Potential of Medicinal Plants and Their Active Components. Biomolecules. 2019;9:10.

15. Petrovska BB. Historical review of medicinal plants' usage. Pharmacogn Rev. 2012;6(11):1-5. doi:10.4103/0973-7847.95849

16. Oh YS. Plant-Derived Compounds Targeting Pancreatic Beta Cells for the Treatment of Diabetes. Evid Based Complement Alternat Med. 2015;2015:629863. doi:10.1155/2015/629863

17. Munhoz ACM, Frode TS. Isolated Compounds from Natural Products with Potential Antidiabetic Activity - A Systematic Review. Curr Diabetes Rev. 2018;14(1):36-106.

18. Qaseem A, Barry MJ, Humphrey LL, Forciea MA. Clinical Guidelines Committee of the American College of P. Oral Pharmacologic Treatment of Type 2 Diabetes Mellitus: A Clinical Practice Guideline Update From the American College of Physicians. Ann Intern Med. 2017;166(4):279-290. doi:10.7326/M16-1860

19. Apostolova N, Iannantuoni F, Gruevska A, Muntane J, Rocha M, Victor VM. Mechanisms of action of metformin in type 2 diabetes: effects on mitochondria and leukocyte-endothelium interactions. Redox Biol. 2020;34:101517. doi:10.1016/j.redox.2020.101517

20. Alam F, Islam MA, Kamal MA, Gan SH. Updates on Managing Type 2 Diabetes Mellitus with Natural Products: towards Antidiabetic Drug Development. Curr Med Chem. 2019;25 (39):5395-5431. doi:10.2174/0929867323666160813222436

21. Chang CLT, Lin Y, Bartolome AP, Chen Y-C, Chiu S-C, Yang W-C. Herbal therapies for type 2 diabetes mellitus: chemistry, biology, and potential application of selected plants and compounds. Evid Based Complement Alternat Med. 2013; 2013:378657. doi:10.1155/2013/378657

22. Singh J, Cumming E, Manoharan G, Kalasz H, Adeghate E. Medicinal chemistry of the anti-diabetic effects of momordica charantia: active constituents and modes of actions. Open Med Chem J. 2011;5(Suppl 2):70-77. doi:10.2174/1874104501105010070

23. Chen H. Oral particulate delivery: status and future trends. $A d v$ Drug Deliv Rev. 1998;34(2-3):339-350. doi:10.1016/S0169409X(98)00047-7

24. Nouri Z, Hajialyani M, Izadi Z, Bahramsoltani R, Farzaei MH, Abdollahi M. Nanophytomedicines for the Prevention of Metabolic Syndrome: A Pharmacological and Biopharmaceutical Review. Front Bioeng Biotechnol. 2020;8:425. 
25. Long J, Song J, Zhang X, et al. Tea saponins as natural stabilizers for the production of hesperidin nanosuspensions. Int J Pharm. 2020;583:119406.

26. Dening TJ, Rao S, Thomas N, Prestidge CA. Oral nanomedicine approaches for the treatment of psychiatric illnesses. $J$ Control Release. 2016;223:137-156.

27. Ochubiojo M, Chinwude I, Ibanga E, Ifianyi S. Nanotechnology in Drug Delivery. Recent Advances in Novel Drug Carrier Systems. 2012.

28. Gutierrez RMP, Mendez JVM, Vazquez IA. Chapter 2 - A novel approach to the oral delivery of bionanostructures for systemic disease. In: Andronescu E, Grumezescu AM, editors. Nanostructures for Oral Medicine. Elsevier; 2017:27-59.

29. Bacanli M, Dilsiz SA, Basaran N, Basaran AA. Effects of phytochemicals against diabetes. Adv Food Nutr Res. 2019;89: 209-238.

30. Ezuruike UF, Prieto JM. The use of plants in the traditional management of diabetes in Nigeria: pharmacological and toxicological considerations. J Ethnopharmacol. 2014;155(2):857-924.

31. Xu L, Li Y, Dai Y, Peng J. Natural products for the treatment of type 2 diabetes mellitus: pharmacology and mechanisms. Pharmacol Res. 2018;130:451-465.

32. Li R, Zhang Y, Rasool S, Geetha T, Babu JR. Effects and Underlying Mechanisms of Bioactive Compounds on Type 2 Diabetes Mellitus and Alzheimer's Disease. Oxid Med Cell Longev. 2019;2019:8165707.

33. Bai L, Li X, He L, et al. Antidiabetic Potential of Flavonoids from Traditional Chinese Medicine: A Review. Am J Chin Med. 2019;47(5):933-957.

34. Wang PC, Zhao S, Yang BY, Wang QH, Kuang HX. Anti-diabetic polysaccharides from natural sources: A review. Carbohydr Polym. 2016;148:86-97.

35. He JH, Chen LX, Li H. Progress in the discovery of naturally occurring anti-diabetic drugs and in the identification of their molecular targets. Fitoterapia. 2019;134:270-289.

36. Tundis R, Loizzo MR, Menichini F. Natural products as alpha-amylase and alpha-glucosidase inhibitors and their hypoglycaemic potential in the treatment of diabetes: an update. Mini Rev Med Chem. 2010;10(4):315-331.

37. Gray GM. Carbohydrate digestion and absorption. Role of the small intestine. N Engl J Med. 1975;292(23):1225-1230.

38. Abbas G, Al Harrasi A, Hussain H, Hamaed A, Supuran CT. The management of diabetes mellitus-imperative role of natural products against dipeptidyl peptidase-4, alpha-glucosidase and sodium-dependent glucose co-transporter 2 (SGLT2). Bioorg Chem. 2019;86:305-315.

39. Blaschek W. Natural Products as Lead Compounds for Sodium Glucose Cotransporter (SGLT) Inhibitors. Planta Med. 2017;83 (12-13):985-993.

40. Moradi-Marjaneh R, Paseban M, Sahebkar A. Natural products with SGLT2 inhibitory activity: possibilities of application for the treatment of diabetes. Phytother Res. 2019;33(10):2518-2530.

41. Gannon NP, Conn CA, Vaughan RA. Dietary stimulators of GLUT4 expression and translocation in skeletal muscle: a mini-review. Mol Nutr Food Res. 2015;59(1):48-64.

42. Hussain T, Tan B, Murtaza G, et al. Flavonoids and type 2 diabetes: evidence of efficacy in clinical and animal studies and delivery strategies to enhance their therapeutic efficacy. Pharmacol Res. 2020;152:104629.

43. Cline GW, Petersen KF, Krssak M, et al. Impaired glucose transport as a cause of decreased insulin-stimulated muscle glycogen synthesis in type 2 diabetes. $N$ Engl J Med. 1999;341(4):240-246.

44. Sayem ASM, Arya A, Karimian H, Krishnasamy N, Ashok Hasamnis A, Hossain CF. Action of Phytochemicals on Insulin Signaling Pathways Accelerating Glucose Transporter (GLUT4) Protein Translocation. Molecules. 2018;23:2.
45. Dominguez Avila JA, Rodrigo Garcia J, Gonzalez Aguilar GA. de la Rosa LA. The Antidiabetic Mechanisms of Polyphenols Related to Increased Glucagon-Like Peptide-1 (GLP1) and Insulin Signaling. Molecules. 2017;22:6.

46. Wani JH, John-Kalarickal J, Fonseca VA. Dipeptidyl Peptidase-4 as a New Target of Action for Type 2 Diabetes Mellitus: A Systematic Review. Cardiology Clinics. 2008;26(4):639-648.

47. Duarte AM, Guarino MP, Barroso S, Gil MM. Phytopharmacological Strategies in the Management of Type 2 Diabetes Mellitus. Foods. 2020;9:3.

48. Jiang CS, Liang LF, Guo YW. Natural products possessing protein tyrosine phosphatase $1 \mathrm{~B}$ (PTP1B) inhibitory activity found in the last decades. Acta Pharmacol Sin. 2012;33(10):1217-1245.

49. Fukunaga T, Zou W, Rohatgi N, Colca JR, Teitelbaum SL. An insulinsensitizing thiazolidinedione, which minimally activates PPAR $\gamma$, does not cause bone loss. J Bone Miner Res. 2015;30(3):481-488.

50. Wang L, Waltenberger B, Pferschy-Wenzig EM, et al. Natural product agonists of peroxisome proliferator-activated receptor gamma (PPAR $\gamma$ ): a review. Biochem Pharmacol. 2014;92(1):73-89.

51. Matsuda H, Nakamura S, Yoshikawa M. Search for new type of PPAR $\gamma$ agonist-like anti-diabetic compounds from medicinal plants. Biol Pharm Bull. 2014;37(6):884-891.

52. Dembinska-Kiec A, Mykkanen O, Kiec-Wilk B, Mykkanen H. Antioxidant phytochemicals against type 2 diabetes. $\mathrm{Br}$ J Nutr. 2008;99 E Suppl 1:ES109-117.

53. Halim M, Halim A. The effects of inflammation, aging and oxidative stress on the pathogenesis of diabetes mellitus (type 2 diabetes). Diabetes Metab Syndr. 2019;13(2):1165-1172.

54. Rahimi-Madiseh M, Malekpour-Tehrani A, Bahmani M, RafieianKopaei M. The research and development on the antioxidants in prevention of diabetic complications. Asian Pac J Trop Med. 2016;9(9):825-831.

55. Dal S, Sigrist S. The Protective Effect of Antioxidants Consumption on Diabetes and Vascular Complications. Diseases. 2016;4:3.

56. Leiherer A, Mundlein A, Drexel H. Phytochemicals and their impact on adipose tissue inflammation and diabetes. Vascul Pharmacol. 2013;58(1-2):3-20.

57. Gothai S, Ganesan P, Park SY, Fakurazi S, Choi DK. Natural Phyto-Bioactive Compounds for the Treatment of Type 2 Diabetes: inflammation as a Target. Nutrients. 2016;8:8.

58. Ahangarpour A, Sayahi M, Sayahi M. The antidiabetic and antioxidant properties of some phenolic phytochemicals: A review study. Diabetes Metab Syndr. 2019;13(1):854-857.

59. Lagoa R, Silva J, Rodrigues JR, Bishayee A. Advances in phytochemical delivery systems for improved anticancer activity. Biotechnol Adv. 2020;38:107382.

60. Rezaeiamiri E, Bahramsoltani R, Rahimi R. Plant-derived natural agents as dietary supplements for the regulation of glycosylated hemoglobin: A review of clinical trials. Clin Nutr. 2020;39 (2):331-342.

61. Xie J, Yang Z, Zhou C, Zhu J, Lee RJ, Teng L. Nanotechnology for the delivery of phytochemicals in cancer therapy. Biotechnol Adv. 2016;34(4):343-353.

62. Ganesan P, Arulselvan P, Choi DK. Phytobioactive compound-based nanodelivery systems for the treatment of type 2 diabetes mellitus current status. Int J Nanomedicine. 2017;12:1097-1111.

63. Pathak S, Regmi S, Nguyen TT, et al. Polymeric microsphere-facilitated site-specific delivery of quercetin prevents senescence of pancreatic islets in vivo and improves transplantation outcomes in mouse model of diabetes. Acta Biomater. 2018;75:287-299.

64. Meena KP, Vijayakumar MR, Dwibedy PS. Catechin-loaded Eudragit microparticles for the management of diabetes: formulation, characterization and in vivo evaluation of antidiabetic efficacy. J Microencapsul. 2017;34(4):342-350. 
65. Chen L, Lin X, Teng H. Emulsions loaded with dihydromyricetin enhance its transport through Caco-2 monolayer and improve anti-diabetic effect in insulin resistant HepG2 cell. Journal of Functional Foods. 2020;64.

66. Zhaojie M, Ming Z, Shengnan W, et al. Amorphous solid dispersion of berberine with absorption enhancer demonstrates a remarkable hypoglycemic effect via improving its bioavailability. Int J Pharm. 2014;467(1-2):50-59.

67. Li J, Du H, Zhang M, et al. Amorphous solid dispersion of Berberine mitigates apoptosis via iPLA2beta/Cardiolipin/Opa1 pathway in $\mathrm{db} / \mathrm{db}$ mice and in Palmitate-treated MIN6 beta-cells. Int J Biol Sci. 2019;15(7):1533-1545.

68. Shulman M, Cohen M, Soto-Gutierrez A, et al. Enhancement of naringenin bioavailability by complexation with hydroxypropyl-betacyclodextrin. [corrected]. PLoS One. 2011;6(4):e18033.

69. Demirdirek B, Uhrich KE. Salicylic acid-based pH-sensitive hydrogels as potential oral insulin delivery systems. J Drug Target. 2015;23(7-8):716-724.

70. Patra JK, Das G, Fraceto LF, et al. Nano based drug delivery systems: recent developments and future prospects J Nanobiotechnology. 2018;16(1):71.

71. Prasad M, Lambe UP, Brar B, et al. Nanotherapeutics: an insight into healthcare and multi-dimensional applications in medical sector of the modern world. Biomed Pharmacother. 2018;97: 1521-1537.

72. Panwar R, Raghuwanshi N, Srivastava AK, Sharma AK, Pruthi V. In-vivo sustained release of nanoencapsulated ferulic acid and its impact in induced diabetes. Mater Sci Eng C Mater Biol Appl. 2018;92:381-392.

73. Akolade JO, Oloyede HOB, Onyenekwe PC. Encapsulation in chitosan-based polyelectrolyte complexes enhances antidiabetic activity of curcumin. Journal of Functional Foods. 2017; 35:584-594.

74. Maity S, Mukhopadhyay P, Kundu PP, Chakraborti AS. Alginate coated chitosan core-shell nanoparticles for efficient oral delivery of naringenin in diabetic animals-An in vitro and in vivo approach. Carbohydr Polym. 2017;170:124-132.

75. Mukhopadhyay P, Maity S, Mandal S, Chakraborti AS, Prajapati AK, Kundu PP. Preparation, characterization and in vivo evaluation of $\mathrm{pH}$ sensitive, safe quercetin-succinylated chitosan-alginate core-shell-corona nanoparticle for diabetes treatment. Carbohydr Polym. 2018;182:42-51.

76. Rani R, Dahiya S, Dhingra D, Dilbaghi N, Kim KH, Kumar S. Improvement of antihyperglycemic activity of nano-thymoquinone in rat model of type-2 diabetes. Chem Biol Interact. 2018;295:119-132.

77. Rani R, Dahiya S, Dhingra D, Dilbaghi N, Kim KH, Kumar S. Evaluation of anti-diabetic activity of glycyrrhizin-loaded nanoparticles in nicotinamide-streptozotocin-induced diabetic rats. Eur J Pharm Sci. 2017;106:220-230.

78. Chitkara D, Nikalaje SK, Mittal A, Chand M, Kumar N. Development of quercetin nanoformulation and in vivo evaluation using streptozotocin induced diabetic rat model. Drug Deliv Transl Res. 2012;2(2):112-123.

79. Kozuka C, Shimizu-Okabe C, Takayama C, et al. Marked augmentation of PLGA nanoparticle-induced metabolically beneficial impact of gamma-oryzanol on fuel dyshomeostasis in genetically obese-diabetic ob/ob mice. Drug Deliv. 2017;24(1):558-568.

80. Mishra SB, Malaviya J, Mukerjee A. Attenuation of Oxidative Stress and Glucose Toxicity by Lutein Loaded Nanoparticles from Spinacia oleracea Leaves. Journal of Pharmaceutical Sciences and Pharmacology. 2015;2(3):242-249.

81. El-Naggar ME, Al-Joufi F, Anwar M, Attia MF, El-Bana MA, Curcumin-loaded PLA. PEG copolymer nanoparticles for treatment of liver inflammation in streptozotocin-induced diabetic rats. Colloids Surf B Biointerfaces. 2019;177:389-398.
82. Paul D, Dey TK, Mukherjee S, Ghosh M, Dhar P. Comparative prophylactic effects of $\alpha$-eleostearic acid rich nano and conventional emulsions in induced diabetic rats. J Food Sci Technol. 2014;51(9):1724-1736.

83. Xu HY, Liu CS, Huang CL, et al. Nanoemulsion improves hypoglycemic efficacy of berberine by overcoming its gastrointestinal challenge. Colloids Surf B Biointerfaces. 2019;181:927-934.

84. Nait Bachir Y, Nait Bachir R, Hadj-Ziane-Zafour A. Nanodispersions stabilized by $\beta$-cyclodextrin nanosponges: application for simultaneous enhancement of bioactivity and stability of sage essential oil. Drug Dev Ind Pharm. 2019;45(2):333-347.

85. Hatanaka J, Chikamori H, Sato H, et al. Physicochemical and pharmacological characterization of $\alpha$-tocopherol-loaded nanoemulsion system. Int J Pharm. 2010;396(1-2):188-193.

86. Garg V, Kaur P, Singh SK, et al. Solid self-nanoemulsifying drug delivery systems for oral delivery of polypeptide-k: formulation, optimization, in-vitro and in-vivo antidiabetic evaluation. Eur J Pharm Sci. 2017;109:297-315.

87. Garg V, Kaur P, Gulati $M$, et al. Coadministration of Polypeptide-k and Curcumin Through Solid Self-Nanoemulsifying Drug Delivery System for Better Therapeutic Effect Against Diabetes Mellitus: formulation, Optimization, Biopharmaceutical Characterization, and Pharmacodynamic Assessment. Assay Drug Dev Technol. 2019;17(4):201-221.

88. Balata GF, Essa EA, Shamardl HA, Zaidan SH, Abourehab MA. Self-emulsifying drug delivery systems as a tool to improve solubility and bioavailability of resveratrol. Drug Des Devel Ther. 2016;10:117-128.

89. Wang H, Li Q, Deng W, et al. Self-nanoemulsifying drug delivery system of trans-cinnamic acid: formulation development and pharmacodynamic evaluation in alloxan-induced type 2 diabetic rat model. Drug Dev Res. 2015;76(2):82-93.

90. Ahangarpour A, Oroojan AA, Khorsandi L, Kouchak M, Badavi M. Solid Lipid Nanoparticles of Myricitrin Have Antioxidant and Antidiabetic Effects on Streptozotocin-Nicotinamide-Induced Diabetic Model and Myotube Cell of Male Mouse. Oxid Med Cell Longev. 2018;2018:7496936.

91. Mohseni R, ArabSadeghabadi Z, Ziamajidi N, Abbasalipourkabir R, RezaeiFarimani A. Oral Administration of Resveratrol-Loaded Solid Lipid Nanoparticle Improves Insulin Resistance Through Targeting Expression of SNARE Proteins in Adipose and Muscle Tissue in Rats with Type 2 Diabetes. Nanoscale Res Lett. 2019;14(1):227.

92. Xue M, Yang MX, Zhang W, et al. Characterization, pharmacokinetics, and hypoglycemic effect of berberine loaded solid lipid nanoparticles. Int J Nanomedicine. 2013;8:4677-4687.

93. Xue M, Zhang L, Yang MX, et al. Berberine-loaded solid lipid nanoparticles are concentrated in the liver and ameliorate hepatosteatosis in $\mathrm{db} / \mathrm{db}$ mice. Int $J$ Nanomedicine. 2015;10:50 49-5057.

94. Piazzini V, Micheli L, Luceri C, et al. Nanostructured lipid carriers for oral delivery of silymarin: improving its absorption and in vivo efficacy in type 2 diabetes and metabolic syndrome model. Int J Pharm. 2019;572:118838.

95. Piazzini V, Lemmi B, D’Ambrosio M, et al. Nanostructured Lipid Carriers as Promising Delivery Systems for Plant Extracts: the Case of Silymarin. Applied Sciences. 2018;8:7.

96. Shi F, Wei Z, Zhao Y, Xu X. Nanostructured Lipid Carriers Loaded with Baicalin: an Efficient Carrier for Enhanced Antidiabetic Effects. Pharmacogn Mag. 2016;12(47):198-202.

97. Amjadi S, Mesgari Abbasi M, Shokouhi B, Ghorbani M, Hamishehkar H. Enhancement of therapeutic efficacy of betanin for diabetes treatment by liposomal nanocarriers. Journal of Functional Foods. 2019;59:119-128. 
98. Pk S. P S, A J, M C, A B. Anti-Diabetic Activity of Lycopene Niosomes: experimental Observation. $J$ Pharm Drug Dev. 2017;4:1.

99. Alam MS, Ahad A, Abidin L, Aqil M, Mir SR, Mujeeb M. Embelin-loaded oral niosomes ameliorate streptozotocin-induced diabetes in Wistar rats. Biomed Pharmacother. 2018;97:15 $14-1520$

100. Singhal T, Mujeeb M, Ahad A, et al. Preparation, optimization and biological evaluation of gymnemic acid loaded niosomes against streptozotocin-nicotinamide induced diabetic-nephropathy in Wistar rats. J Drug Deliv Sci Technol. 2019;54.

101. Yu F, Li Y, Chen Q, et al. Monodisperse microparticles loaded with the self-assembled berberine-phospholipid complex-based phytosomes for improving oral bioavailability and enhancing hypoglycemic efficiency. Eur J Pharm Biopharm. 2016;10 3:136-148. doi:10.1016/j.ejpb.2016.03.019

102. Zhang J, Zhou J, Zhang T, et al. Facile Fabrication of an Amentoflavone-Loaded Micelle System for Oral Delivery To Improve Bioavailability and Hypoglycemic Effects in KKAy Mice. ACS Appl Mater Interfaces. 2019;11(13):12904-12913. doi:10.1021/acsami.9b03275

103. Singh J, Mittal P, Vasant Bonde G, Ajmal G, Mishra B. Design, optimization, characterization and in-vivo evaluation of Quercetin enveloped Soluplus ${ }^{\mathbb{B}} / \mathrm{P} 407$ micelles in diabetes treatment. Artif Cells Nanomed Biotechnol. 2018;46(sup3):S546-S555. doi:10.10 80/21691401.2018.1501379

104. El-Far YM, Zakaria MM, Gabr MM, El Gayar AM, El-Sherbiny IM, Eissa LA. A newly developed silymarin nanoformulation as a potential antidiabetic agent in experimental diabetes. Nanomedicine. 2016;11(19):2581-2602. doi:10.2217/nnm-20160204

105. El-Far YM, Zakaria MM, Gabr MM, El Gayar AM, Eissa LA, ElSherbiny IM. Nanoformulated natural therapeutics for management of streptozotocin-induced diabetes: potential use of curcumin nanoformulation. Nanomedicine. 2017;12(14):1689-1711. doi:10.2217/nnm-2017-0106

106. Akbar MU, Zia KM, Akash MSH, Nazir A, Zuber M, Ibrahim M. In-vivo anti-diabetic and wound healing potential of chitosan/ alginate/maltodextrin/pluronic-based mixed polymeric micelles: curcumin therapeutic potential. Int J Biol Macromol. 2018;120 (Pt B):2418-2430. doi:10.1016/j.ijbiomac.2018.09.010

107. Hussein J, Attia MF, El Bana M, et al. Solid state synthesis of docosahexaenoic acid-loaded zinc oxide nanoparticles as a potential antidiabetic agent in rats. Int J Biol Macromol. 2019;140:1305-1314. doi:10.1016/j.ijbiomac.2019.08.201

108. Liu Y, Zeng S, Liu Y, et al. Synthesis and antidiabetic activity of selenium nanoparticles in the presence of polysaccharides from Catathelasma ventricosum. Int J Biol Macromol. 2018;11 4:632-639. doi:10.1016/j.ijbiomac.2018.03.161

109. Yin J, Hou Y, Yin Y, Song X. Selenium-coated nanostructured lipid carriers used for oral delivery of berberine to accomplish a synergic hypoglycemic effect. Int $J$ Nanomedicine. 2017;12:8671-8680. doi:10.2147/IJN.S144615

110. Huang P-K, Lin S-X, Tsai M-J, et al. Encapsulation of 16-Hydroxycleroda-3,13-Dine-16,15-Olide in Mesoporous Silica Nanoparticles as a Natural Dipeptidyl Peptidase-4 Inhibitor Potentiated Hypoglycemia in Diabetic Mice. Nanomaterials. 2017;7(5):5. doi:10.3390/nano7050112

111. Gouda W, Hafiz NA, Mageed L, et al. Effects of nano-curcumin on gene expression of insulin and insulin receptor. Bulletin Nat Res Centre. 2019;43(1):1. doi:10.1186/s42269-019-0164-0

112. Abu-Taweel GM, Attia MF, Hussein J, et al. Curcumin nanoparticles have potential antioxidant effect and restore tetrahydrobiopterin levels in experimental diabetes. Biomed Pharm. $2020 ; 131$.
113. Singh AK, Pandey H, Ramteke PW, Mishra SB. Nano-suspension of ursolic acid for improving oral bioavailability and attenuation of type II diabetes: A histopathological investigation. Biocatalysis and Agricultural Biotechnology. 2019;2:22.

114. Wang Z, Wu J, Zhou Q, Wang Y, Chen T. Berberine nanosuspension enhances hypoglycemic efficacy on streptozotocin induced diabetic C57BL/6 mice. Evid Based Complement Alternat Med. 2015;2015:239749.

115. Ravichandran R. Studies on Gymnemic Acids Nanoparticulate Formulations Against Diabetes Mellitus. Int J Biomed Clin Eng. 2012;1(2):1-12. doi:10.4018/ijbce.2012070101

116. Zhao X, Wang W, Zu Y, et al. Preparation and characterization of betulin nanoparticles for oral hypoglycemic drug by antisolvent precipitation. Drug Deliv. 2014;21(6):467-479. doi:10.3109/ 10717544.2014.881438

117. Banik BL, Fattahi P, Brown JL. Polymeric nanoparticles: the future of nanomedicine. Wiley Interdiscip Rev Nanomed Nanobiotechnol. 2016;8(2):271-299. doi:10.1002/wnan.1364

118. Katuwavila NP, Perera ADLC, Samarakoon SR, et al. ChitosanAlginate Nanoparticle System Efficiently Delivers Doxorubicin to MCF-7 Cells. Journal of Nanomaterials. 2016;2016:1-12.

119. Jao D, Xue Y, Medina J, Protein-Based Drug-Delivery HX. Materials. Materials (Basel. 2017;10:5.

120. Fonte P, Araujo F, Silva C, et al. Polymer-based nanoparticles for oral insulin delivery: revisited approaches. Biotechnol $A d v$. 2015;33(6):1342-1354. doi:10.1016/j.biotechadv.2015.02.010

121. Sami El-banna F, Mahfouz ME, Leporatti S, El-Kemary M, Hanafy AN. N. Chitosan as a Natural Copolymer with Unique Properties for the Development of Hydrogels. Applied Sciences. 2019;9(11):11. doi:10.3390/app9112193

122. Rizeq BR, Younes NN, Rasool K, Nasrallah GK. Synthesis, Bioapplications, and Toxicity Evaluation of Chitosan-Based Nanoparticles. Int J Mol Sci. 2019;20(22):22. doi:10.3390/ijms20 225776

123. George A, Shah PA, Shrivastav PS. Natural biodegradable polymers based nano-formulations for drug delivery: A review. Int J Pharm. 2019;561:244-264. doi:10.1016/j.jpharm.2019.03.011

124. Chauhan P, Tamrakar AK, Mahajan S, Prasad G. Chitosan encapsulated nanocurcumin induces GLUT-4 translocation and exhibits enhanced anti-hyperglycemic function. Life Sci. 2018;213: 226-235. doi:10.1016/j.lfs.2018.10.027

125. Sonia TA, Sharma CP. An overview of natural polymers for oral insulin delivery. Drug Discov Today. 2012;17(13-14):784-792. doi:10.1016/j.drudis.2012.03.019

126. Karlsson J, Vaughan HJ, Green JJ. Biodegradable Polymeric Nanoparticles for Therapeutic Cancer Treatments. Annu Rev Chem Biomol Eng. 2018;9(1):105-127. doi:10.1146/annurevchembioeng-060817-084055

127. Wang W, Meng Q, Li Q, et al. Chitosan Derivatives and Their Application in Biomedicine. Int J Mol Sci. 2020;21:2.

128. Zhu W, Zhang Z. Preparation and characterization of catechin-grafted chitosan with antioxidant and antidiabetic potential. Int $J$ Biol Macromol. 2014;70:150-155. doi:10.1016/j.ijbiomac.2014.06.047

129. Muzzarelli RAA, Chitosan Chemistry MC. Relevance to the Biomedical Sciences. In: Polysaccharides I. 2005;2:151-209.

130. Severino P, da Silva CF, Andrade LN, de Lima Oliveira D, Campos J, Souto EB. Alginate Nanoparticles for Drug Delivery and Targeting. Curr Pharm Des. 2019;25(11):1312-1334.

131. Bassas-Galia M, Follonier S, Pusnik M, Zinn M. 2 - Natural polymers: A source of inspiration. In: Perale G, Hilborn J, editors. Bioresorbable Polymers for Biomedical Applications. Woodhead Publishing; 2017:31-64.

132. Mandaogade PM, Satturwar PM, Fulzele SV, Gogte BB, Dorle AK. Rosin derivatives: novel film forming materials for controlled drug delivery. Reactive and Functional Polymers. 2002;50(3):233-242. doi:10.1016/S1381-5148(01)00117-1 
133. Rani R, Dahiya S, Dhingra D, et al. $<\mathrm{p}>$ Antidiabetic activity enhancement in streptozotocin + nicotinamide-induced diabetic rats through combinational polymeric nanoformulation. Int $J$ Nanomedicine. 2019;14:4383-4395. doi:10.2147/IJN.S205319

134. Fan Z, Cheng P, Liu M, et al. Dynamic crosslinked and injectable biohydrogels as extracellular matrix mimics for the delivery of antibiotics and 3D cell culture. RSC Advances. 2020;10 (33):19587-19599. doi:10.1039/D0RA02218G

135. Hamid Akash MS, Rehman K, Chen CS. Natural and Synthetic Polymers as Drug Carriers for Delivery of Therapeutic Proteins. Polymer Rev. 2015;55(3):371-406. doi:10.1080/15583724.2014. 995806

136. Kapoor R, Singh S, Tripathi M, Bhatnagar P, Kakkar P, Gupta KC. O-hexadecyl-dextran entrapped berberine nanoparticles abrogate high glucose stress induced apoptosis in primary rat hepatocytes. PLoS One. 2014;9(2):e89124. doi:10.1371/journal. pone.0089124

137. Kamaly N, Yameen B, Wu J, Farokhzad OC. Degradable Controlled-Release Polymers and Polymeric Nanoparticles: mechanisms of Controlling Drug Release. Chem Rev. 2016;116 (4):2602-2663. doi:10.1021/acs.chemrev.5b00346

138. Angelova N, Hunkeler D. Rationalizing the design of polymeric biomaterials. Trends in Biotechnology. 1999;17(10):409-421. doi:10.1016/S0167-7799(99)01356-6

139. Obayemi JD, Jusu SM, Salifu AA, et al. Degradable porous drug-loaded polymer scaffolds for localized cancer drug delivery and breast cell/tissue growth. Mater Sci Eng C Mater Biol Appl. 2020;112:110794. doi:10.1016/j.msec.2020.110794

140. Washington KE, Kularatne RN, Karmegam V, Biewer MC, Stefan MC. Recent advances in aliphatic polyesters for drug delivery applications. Wiley Interdiscip Rev Nanomed Nanobiotechnol. 2017;9(4):4. doi:10.1002/wnan.1446

141. Mir M, Ahmed N, Rehman AU. Recent applications of PLGA based nanostructures in drug delivery. Colloids Surf B Biointerfaces. 2017;159:217-231. doi:10.1016/j.colsurfb.2017.07.038

142. Samadder A, Abraham SK, Khuda-Bukhsh AR. Nanopharmaceutical approach using pelargonidin towards enhancement of efficacy for prevention of alloxan-induced DNA damage in L6 cells via activation of PARP and p53. Environ Toxicol Pharmacol. 2016;43:27-37. doi:10.1016/j.etap.2016.02.010

143. Torché A-M, Jouan H, Le Corre P, et al. Ex vivo and in situ PLGA microspheres uptake by pig ileal Peyer's patch segment. Int J Pharm. 2000;201(1):15-27. doi:10.1016/S0378-5173(00) 00364-1

144. Ismail R, Bocsik A, Katona G, Grof I, Deli MA, Csoka I. Encapsulation in Polymeric Nanoparticles Enhances the Enzymatic Stability and the Permeability of the GLP-1 Analog, Liraglutide, Across a Culture Model of Intestinal Permeability. Pharmaceutics. 2019;11(11):11. doi:10.3390/pharmaceutics11110599

145. Nagarajan V, Mohanty AK, Misra M. Perspective on Polylactic Acid (PLA) based Sustainable Materials for Durable Applications: focus on Toughness and Heat Resistance. ACS Sustainable Chemistry \& Engineering. 2016;4(6):2899-2916. doi:10.1021/acssuschemeng.6b00321

146. Vroman I, Tighzert L. Biodegradable Polymers. Materials. 2009;2(2):307-344. doi:10.3390/ma2020307

147. Barwal I, Sood A, Sharma M, Singh B, Yadav SC. Development of stevioside Pluronic-F-68 copolymer based PLA-nanoparticles as an antidiabetic nanomedicine. Colloids Surf B Biointerfaces. 2013;101:510-516. doi:10.1016/j.colsurfb.2012.07.005

148. Ponsart S, Coudane J, Vert M. A novel route to poly( $\varepsilon$ caprolactone)-based copolymers via anionic derivatization. Biomacromolecules. 2000;1(2):275-281. doi:10.1021/bm005521t

149. Weissenbock A, Wirth M, Gabor F. Pluronic ${ }^{\circledR}$ F-68 Enhances the Nanoparticle-Cell Interaction. J Control Release. 2004;99 (3):383-392.
150. Barwal I, Yadav YS. Rebaudioside A Loaded Poly-D, L-LactideNanoparticles as an Anti-Diabetic Nanomedicine. Journal of Bionanoscience. 2014;8(2):137-140. doi:10.1166/jbns.2014.1212

151. Gholipour Kanani A, Bahrami SH. Effect of Changing Solvents on Poly(-Caprolactone) Nanofibrous Webs Morphology. Journal of Nanomaterials. 2011;2011:1-10. doi:10.1155/2011/724153

152. Kamaraj N, Rajaguru PY, Issac PK, Sundaresan S. Fabrication, characterization, in vitro drug release and glucose uptake activity of 14-deoxy, 11, 12-didehydroandrographolide loaded polycaprolactone nanoparticles. Asian J Pharm Sci. 2017;12(4):353-362. doi:10.1016/j.ajps.2017.02.003

153. Chen W, Hou Y, Tu Z, Gao L, Haag R. pH-degradable PVA-based nanogels via photo-crosslinking of thermo-preinduced nanoaggregates for controlled drug delivery. Journal of Controlled Release. 2017;259:160-167. doi:10.1016/j.jconrel.2016.10.032

154. Sharma P, Sen D, Neelakantan V, Shankar V, Jhunjhunwala S. Disparate effects of PEG or albumin based surface modification on the uptake of nano- and micro-particles. Biomater Sci. 2019;7 (4):1411-1421. doi:10.1039/C8BM01545G

155. Masood F. Polymeric nanoparticles for targeted drug delivery system for cancer therapy. Mater Sci Eng C Mater Biol Appl. 2016;60:569-578. doi:10.1016/j.msec.2015.11.067

156. Ahlawat J, Henriquez G, Narayan M. Enhancing the Delivery of Chemotherapeutics: role of Biodegradable Polymeric Nanoparticles. Molecules. 2018;23(9):9. doi:10.3390/molecules23092157

157. Sechi M, Syed DN, Pala N, et al. Nanoencapsulation of dietary flavonoid fisetin: formulation and in vitro antioxidant and $\alpha$ glucosidase inhibition activities. Mater Sci Eng C Mater Biol Appl. 2016;68:594-602. doi:10.1016/j.msec.2016.06.042

158. Sanna V, Siddiqui IA, Sechi M, Mukhtar H. Resveratrol-Loaded Nanoparticles Based on Poly(epsilon-caprolactone) and Poly(d, 1-lactic-glycolic acid)-Poly(ethylene glycol) Blend for Prostate Cancer Treatment. Mol Pharm. 2013;10(10):3871-3881. doi:10. 1021/mp400342f

159. Kong L, Campbell F, Kros A. DePEGylation strategies to increase cancer nanomedicine efficacy. Nanoscale Horiz. 2019;4 (2):378-387. doi:10.1039/C8NH00417J

160. Carbone JP, Reinert KH. Synthetic Polymers. In: Reference Module in Earth Systems and Environmental Sciences. Elsevier; 2015.

161. Davatgaran-Taghipour Y, Masoomzadeh S, Farzaei $\mathrm{MH}$, et al. Polyphenol nanoformulations for cancer therapy: experimental evidence and clinical perspective. Int $J$ Nanomedicine. 2017;12:2689-2702. doi:10.2147/IJN.S131973

162. Cerpnjak K, Zvonar A, Gasperlin M, Vrecer F. Lipid-based systems as a promising approach for enhancing the bioavailability of poorly water-soluble drugs. Acta Pharm. 2013;63(4):427-445. doi:10.2478/acph-2013-0040

163. Talegaonkar S, Bhattacharyya A. Potential of Lipid Nanoparticles (SLNs and NLCs) in Enhancing Oral Bioavailability of Drugs with Poor Intestinal Permeability. AAPS PharmSciTech. 2019;20 (3):121. doi:10.1208/s12249-019-1337-8

164. Jia JL. Nanoparticle Formulation Increases Oral Bioavailability of Poorly Soluble Drugs: approaches, Experimental Evidences and Theory. Curr Nanosci. 2005;1(3):237-243. doi:10.2174/15734 1305774642939

165. Gordillo-Galeano A, Mora-Huertas CE. Solid lipid nanoparticles and nanostructured lipid carriers: A review emphasizing on particle structure and drug release. Eur J Pharm Biopharm. 2018;133:285-308. doi:10.1016/j.ejpb.2018.10.017

166. Sanchez-Lopez E, Guerra M, Dias-Ferreira J, et al. Current Applications of Nanoemulsions in Cancer Therapeutics. Nanomaterials. 2019;9(6):6. doi:10.3390/nano9060821

167. Pavoni L, Perinelli DR, Bonacucina G, Cespi M, Palmieri GF. An Overview of Micro- and Nanoemulsions as Vehicles for Essential Oils: formulation, Preparation and Stability. Nanomaterials. 2020; 10(1):1. doi:10.3390/nano10010135 
168. Salvia-Trujillo L, Soliva-Fortuny R, Rojas-Grau MA, McClements DJ, Martín-Belloso M-BO. Edible Nanoemulsions as Carriers of Active Ingredients: A Review. Annu Rev Food Sci Technol. 2017;8(1):439-466. doi:10.1146/annurev-food-030216025908

169. Jiang X-C, Gao J-Q. Exosomes as novel bio-carriers for gene and drug delivery. Int J Pharm. 2017;521(1-2):167-175. doi:10.1016/ j.ijpharm.2017.02.038

170. Singh Y, Meher JG, Raval K, et al. Nanoemulsion: concepts, development and applications in drug delivery. $J$ Control Release. 2017;252:28-49. doi:10.1016/j.jconrel.2017.03.008

171. Trotta F, Dianzani C, Caldera F, Mognetti B, Cavalli R. The application of nanosponges to cancer drug delivery. Expert Opin Drug Deliv. 2014;11(6):931-941. doi:10.1517/17425247.2014. 911729

172. Krabicova I, Appleton SL, Tannous M, et al. History of Cyclodextrin Nanosponges. Polymers (Basel. 2020;12(5):5. doi:10.3390/polym 12051122

173. Pawar S, Shende P, Trotta F. Diversity of $\beta$-cyclodextrin-based nanosponges for transformation of actives. Int $J$ Pharm. 2019;565:333-350. doi:10.1016/j.ijpharm.2019.05.015

174. Karthik P, Ezhilarasi PN, Anandharamakrishnan C. Challenges associated in stability of food grade nanoemulsions. Crit Rev Food Sci Nutr. 2017;57(7):1435-1450. doi:10.1080/10408398.20 15.1006767

175. Rehman FU, Shah KU, Shah SU, Khan IU, Khan GM, Khan A. From nanoemulsions to self-nanoemulsions, with recent advances in self-nanoemulsifying drug delivery systems (SNEDDS). Expert Opin Drug Deliv. 2017;14(11):1325-1340. doi:10.1080/17425 247.2016.1218462

176. Gupta A, Eral HB, Hatton TA, Doyle PS. Nanoemulsions: formation, properties and applications. Soft Matter. 2016;12 (11):2826-2841. doi:10.1039/C5SM02958A

177. Tayeb HH, Sainsbury F. Nanoemulsions in drug delivery: formulation to medical application. Nanomedicine. 2018;13(19):25 07-2525. doi:10.2217/nnm-2018-0088

178. Dokania S, Joshi AK. Self-microemulsifying drug delivery system (SMEDDS) - challenges and road ahead. Drug Deliv. 2015;22(6):675-690. doi:10.3109/10717544.2014.896058

179. Alghananim A, Ozalp Y, Mesut B, Serakinci N, Ozsoy Y, Gungor S. A Solid Ultra Fine Self-Nanoemulsifying Drug Delivery System (S-SNEDDS) of Deferasirox for Improved Solubility: optimization, Characterization, and In Vitro Cytotoxicity Studies. Pharmaceuticals. 2020;13(8):8. doi:10.33 90/ph13080162

180. Date AA, Desai N, Dixit R, Nagarsenker M. Selfnanoemulsifying drug delivery systems: formulation insights, applications and advances. Nanomedicine. 2010;5(10):15 95-1616. doi: $10.2217 / \mathrm{nnm} .10 .126$

181. Date AA, Nagarsenker MS. Design and evaluation of self-nanoemulsifying drug delivery systems (SNEDDS) for cefpodoxime proxetil. Int $J$ Pharm. 2007;329(1-2):166-172. doi:10.1016/j.ijpharm.2006.08.038

182. Cherniakov I, Domb AJ, Hoffman A. Self-nano-emulsifying drug delivery systems: an update of the biopharmaceutical aspects. Expert Opin Drug Deliv. 2015;12(7):1121-1133. doi:10.1517/ 17425247.2015.999038

183. Chatterjee B, Hamed Almurisi S, Ahmed Mahdi Dukhan A, Mandal UK, Sengupta P. Ahmed Mahdi Dukhan A, Mandal UK, Sengupta P. Controversies with self-emulsifying drug delivery system from pharmacokinetic point of view. Drug Deliv. 2016;23(9):3639-3652. doi:10.1080/10717544.2016.1214990

184. Kumar R, Khursheed R, Kumar R, et al. Self-nanoemulsifying drug delivery system of fisetin: formulation, optimization, characterization and cytotoxicity assessment. J Drug Deliv Sci Technol. 2019;54.
185. Kumar B, Garg V, Singh S, et al. Impact of spray drying over conventional surface adsorption technique for improvement in micromeritic and biopharmaceutical characteristics of self-nanoemulsifying powder loaded with two lipophilic as well as gastrointestinal labile drugs. Powder Technology. 2018;32 6:425-442. doi:10.1016/j.powtec.2017.12.005

186. Khursheed R, Singh SK, Wadhwa S, et al. Exploring role of probiotics and Ganoderma lucidum extract powder as solid carriers to solidify liquid self-nanoemulsifying delivery systems loaded with curcumin. Carbohydr Polym. 2020;250:116996. doi:10.1016/j.carbpol.2020.116996

187. Sadegh Malvajerd S, Azadi A, Izadi Z, et al. Brain Delivery of Curcumin Using Solid Lipid Nanoparticles and Nanostructured Lipid Carriers: preparation, Optimization, and Pharmacokinetic Evaluation. ACS Chem Neurosci. 2019;10(1):728-739. doi:10.10 21/acschemneuro. 8 b00510

188. Garces A, Amaral MH, Sousa Lobo JM, Silva AC. Formulations based on solid lipid nanoparticles (SLN) and nanostructured lipid carriers (NLC) for cutaneous use: A review. Eur J Pharm Sci. 2018;112:159-167. doi:10.1016/j.ejps.2017.11.023

189. Ghasemiyeh P, Mohammadi-Samani S. Solid lipid nanoparticles and nanostructured lipid carriers as novel drug delivery systems: applications, advantages and disadvantages. Res Pharm Sci. 2018;13(4):288-303. doi:10.4103/1735-5362.235156

190. Tapeinos C, Battaglini M, Ciofani G. Advances in the design of solid lipid nanoparticles and nanostructured lipid carriers for targeting brain diseases. J Control Release. 2017;264:306-332. doi:10.1016/j.jconrel.2017.08.033

191. Khosa A, Reddi S, Saha RN. Nanostructured lipid carriers for site-specific drug delivery. Biomed Pharmacother. 2018;103: 598-613. doi:10.1016/j.biopha.2018.04.055

192. Soussan E, Cassel S, Blanzat M, Rico-Lattes I. Drug delivery by soft matter: matrix and vesicular carriers. Angew Chem Int Ed Engl. 2009;48(2):274-288. doi:10.1002/anie.200802453

193. Elizondo E, Moreno E, Cabrera I, et al. Liposomes and other vesicular systems: structural characteristics, methods of preparation, and use in nanomedicine. Prog Mol Biol Transl Sci. 2011;104:1-52.

194. Kapoor B, Gupta R, Singh SK, Gulati M, Singh S. Prodrugs, phospholipids and vesicular delivery - An effective triumvirate of pharmacosomes. Adv Colloid Interface Sci. 2018;253:35-65. doi:10.1016/j.cis.2018.01.003

195. Kapoor B, Gupta R, Gulati M, Singh SK, Khursheed R, Gupta M. The Why, Where, Who, How, and What of the vesicular delivery systems. Adv Colloid Interface Sci. 2019;271:101985. doi:10.10 16/j.cis.2019.07.006

196. Aloulou A, Ali YB, Bezzine S, Gargouri Y, Gelb MH. Phospholipases: an overview. Methods Mol Biol. 2012;861:63-85.

197. Li T, Cipolla D, Rades T, Boyd BJ. Drug nanocrystallisation within liposomes. $J$ Control Release. 2018;288:96-110. doi:10.1016/j.jconrel.2018.09.001

198. Gnananath K, Sri Nataraj K, Ganga Rao B. Phospholipid Complex Technique for Superior Bioavailability of Phytoconstituents. Adv Pharm Bull. 2017;7(1):35-42.

199. Li M, Du C, Guo N, et al. Composition design and medical application of liposomes. Eur J Med Chem. 2019;164:640-653. doi:10.1016/j.ejmech.2019.01.007

200. Yucel Ç, Karatoprak GŞ, Aktas Y. Nanoliposomal Resveratrol as a Novel Approach to Treatment of Diabetes Mellitus. J Nanosci Nanotechnol. 2018;18(6):3856-3864. doi:10.1166/jnn.2018.15 247

201. Asprea M, Tatini F, Piazzini V, Rossi F, Bergonzi MC, Bilia AR. Stable, Monodisperse, and Highly Cell-Permeating Nanocochleates from Natural Soy Lecithin Liposomes. Pharmaceutics. 2019;11(1):1. doi:10.3390/pharmaceutics 11010 034 
202. Zhong X, Chen B, Yang Z. Nanocochleates as the Potential Delivery Systems for Oral Antitumor of Hydroxycamptothecin. J Biomed Nanotechnol. 2018;14(7):1339-1346. doi:10.1166/ jbn.2018.2572

203. Bhosale RR, Ghodake PP, Mane AN, Ghadge AA. Nanocochleates: A novel carrier for drug transfer. $J$ surg. 2013;2(5):964-969.

204. Bothiraja C, Yojana BD, Pawar AP, Shaikh KS, Thorat UH. Fisetin-loaded nanocochleates: formulation, characterisation, in anticancer testing, bioavailability and biodistribution study. Expert Opin Drug Deliv. 2014;11(1):17-29. doi:10.1517/ 17425247.2013.860131

205. Shende P, Khair R, Gaud RS. Nanostructured cochleates: a multi-layered platform for cellular transportation of therapeutics. Drug Dev Ind Pharm. 2019;45(6):869-881. doi:10.1080/ 03639045.2019.1583757

206. Ç YÜCEL, GŞ KARATOPRAK, Atmar A. Novel Resveratrol-Loaded Nanocochleates and Effectiveness in the Treatment of Diabetes. Fabad Journal of Pharmaceutical Sciences. 2018;43(2):35-44.

207. Bozo T, Wacha A, Mihaly J, Bota A, Kellermayer MSZ. Dispersion and stabilization of cochleate nanoparticles. Eur J Pharm Biopharm. 2017;117:270-275. doi:10.1016/j.ejpb.20 17.04.030

208. Mahale NB, Thakkar PD, Mali RG, Walunj DR, Chaudhari SR Niosomes: novel sustained release nonionic stable vesicular systems - an overview. Adv Colloid Interface Sci. 2012;183184:46-54. doi:10.1016/j.cis.2012.08.002

209. Pk S, P PS. Novel Encapsulation of Lycopene in Niosomes and Assessment of its Anticancer Activity. Journal of Bioequivalence \& Bioavailability. 2016;8(5):5. doi:10.4172/jbb.1000300

210. Ghanbarzadeh B, Babazadeh A, Hamishehkar H. Nanophytosome as a potential food-grade delivery system. Food Bioscience. 2016;15:126-135. doi:10.1016/j.fbio.2016.07.006

211. Lu M, Qiu Q, Luo X, et al. Phyto-phospholipid complexes (phytosomes): A novel strategy to improve the bioavailability of active constituents. Asian J Pharm Sci. 2019;14(3):265-274. doi:10.1016/j.ajps.2018.05.011

212. Mirzaei H, Shakeri A, Rashidi B, Jalili A, Banikazemi Z, Sahebkar A. Phytosomal curcumin: A review of pharmacokinetic, experimental and clinical studies. Biomed Pharmacother. 2017;85:102-112. doi:10.1016/j.biopha.2016.11.098

213. Babazadeh A, Zeinali M, Hamishehkar HH. Nano-Phytosome: A Developing Platform for Herbal Anti-Cancer Agents in Cancer Therapy. Curr Drug Targets. 2018;19(2):170-180. doi:10.2174/1389450118666170508095250

214. Kim S-M, Jung J-I, Chai C, Imm J-Y. Characteristics and Glucose Uptake Promoting Effect of Chrysin-Loaded Phytosomes Prepared with Different Phospholipid Matrices. Nutrients. 2019;11(10):10. doi:10.3390/nu11102549

215. Torchilin VP, Lukyanov AN, Gao Z, Papahadjopoulos-Sternberg B. Immunomicelles: targeted pharmaceutical carriers for poorly soluble drugs. Proc Natl Acad Sci U S A. 2003;100 (10):6039-6044. doi:10.1073/pnas.0931428100

216. Simoes SM, Figueiras AR, Veiga F, Concheiro A, AlvarezLorenzo C. Polymeric micelles for oral drug administration enabling locoregional and systemic treatments. Expert Opin Drug Deliv. 2015;12(2):297-318. doi:10.1517/17425247.2015. 960841

217. Reddy BP, Yadav HKS, Nagesha DK, Raizaday A, Karim A. Polymeric Micelles as Novel Carriers for Poorly Soluble Drugs - review. J Nanosci Nanotechnol. 2015;15(6):4009-4018. doi:10.1166/jnn.2015.9713

218. Cho H, Lai TC, Tomoda K, Kwon GS. Polymeric micelles for multi-drug delivery in cancer. AAPS PharmSciTech. 2015;16 (1):10-20. doi:10.1208/s12249-014-0251-3
219. Han J, Oh J, Ihm S-H S-H, Lee M. Peptide micelle-mediated curcumin delivery for protection of islet $\beta$-cells under hypoxia. Journal of Drug Targeting. 2016;24(7):618-623. doi:10.3109/ 1061186X.2015.1132220

220. Tousif Ayyub K, Moravkar K, Maniruzzaman M, Amin P. Effect of melt extrudability and melt binding efficiency of polyvinyl caprolactam polyvinyl acetate polyethylene glycol graft copolymer (Soluplus ${ }^{\circledR}$ ) on release pattern of hydrophilic and high dose drugs. Mater Sci Eng C Mater Biol Appl. 2019;99:563-574. doi:10.1016/j.msec.2019.01.126

221. Li Z-L, Peng S-F, Chen X, et al. Pluronics modified liposomes for curcumin encapsulation: sustained release, stability and bioaccessibility. Food Res Int. 2018;108:246-253. doi:10.1016/j. foodres.2018.03.048

222. Batrakova EV, Kabanov AV. Pluronic block copolymers: evolution of drug delivery concept from inert nanocarriers to biological response modifiers. J Control Release. 2008;130(2):98-106. doi:10.1016/j.jconrel.2008.04.013

223. Lu Y, Yue Z, Xie J, et al. Micelles with ultralow critical micelle concentration as carriers for drug delivery. Nat Biomed Eng. 2018;2(5):318-325. doi:10.1038/s41551-018-0234-x

224. Fernandez-Pineiro I, Badiola I, Sanchez A. Nanocarriers for microRNA delivery in cancer medicine. Biotechnol Adv. 2017;35(3):350-360. doi:10.1016/j.biotechadv.2017.03.002

225. Sabio RM, Meneguin AB, Ribeiro TC, Silva RR, Chorilli M. New insights towards mesoporous silica nanoparticles as a technological platform for chemotherapeutic drugs delivery. Int $J$ Pharm. 2019;564:379-409. doi:10.1016/j.ijpharm.2019.04.067

226. Ahmed HH, Abd El-Maksoud MD, Abdel Moneim AE, Aglan HA. Pre-Clinical Study for the Antidiabetic Potential of Selenium Nanoparticles. Biol Trace Elem Res. 2017;177 (2):267-280. doi:10.1007/s12011-016-0876-z

227. Al-Quraishy S, Dkhil MA, Abdel Moneim AE. Antihyperglycemic activity of selenium nanoparticles in streptozotocin-induced diabetic rats. Int $J$ Nanomedicine. 2015;10:6741-6756.

228. Uma Suganya KS, Govindaraju K, Veena Vani C, Premanathan M, Ganesh Kumar VK. In vitro biological evaluation of anti-diabetic activity of organic-inorganic hybrid gold nanoparticles. IET Nanobiotechnol. 2019;13(2):226-229. doi:10.1049/iet-nbt.2018.5139

229. Hussein JS, Rasheed W, Ramzy T, et al. Synthesis of docosahexaenoic acid-loaded silver nanoparticles for improving endothelial dysfunctions in experimental diabetes. Hum Exp Toxicol. 2019;38 (8):962-973. doi:10.1177/0960327119843586

230. Hussein J, El-Naggar ME, Latif YA, et al. Solvent-free and one-pot synthesis of silver and zinc oxide nanoparticles: activity toward cell membrane component and insulin signaling pathway in experimental diabetes. Colloids and Surfaces B: Biointerfaces. 2018;170:76-84. doi:10.1016/j.colsurfb.2018.05.058

231. Alkaladi A, Abdelazim AM, Afifi M. Antidiabetic activity of zinc oxide and silver nanoparticles on streptozotocin-induced diabetic rats. Int J Mol Sci. 2014;15(2):2015-2023. doi:10.3390/ijms15022015

232. Lushchak O, Zayachkivska A, Vaiserman A. Metallic Nanoantioxidants as Potential Therapeutics for Type 2 Diabetes: A Hypothetical Background and Translational Perspectives. Oxid Med Cell Longev. 2018;2018:3407375. doi:10.1155/2018/ 3407375

233. Hanan NA, Chiu HI, Ramachandran MR, et al. Cytotoxicity of Plant-Mediated Synthesis of Metallic Nanoparticles: A Systematic Review. Int J Mol Sci. 2018;19(6):6. doi:10.3390/ ijms 19061725

234. Anand K, Tiloke C, Naidoo P, Chuturgoon AA. Phytonanotherapy for management of diabetes using green synthesis nanoparticles. J Photochem Photobiol B. 2017;173:626-639. doi:10.1016/j. jphotobiol.2017.06.028 
235. Rajarajeshwari T, Shivashri C, Rajasekar P. Synthesis and characterization of biocompatible gymnemic acid-gold nanoparticles: a study on glucose uptake stimulatory effect in 3T3-L1 adipocytes. RSC Adv. 2014;4(108):63285-63295. doi:10.1039/C4RA07087A

236. Chockalingam S, Thada R, Dhandapani RK, Panchamoorthy R. Biogenesis, characterization, and the effect of vicenin-gold nanoparticles on glucose utilization in 3T3-L1 adipocytes: a bioinformatic approach to illuminate its interaction with PTP 1B and AMPK. Biotechnology Progress. 2015;31(4):1096-1106. doi:10.1002/btpr.2112

237. Shamprasad BR, Keerthana S, Megarajan S, Lotha R, Aravind S, Veerappan A. Photosynthesized escin stabilized gold nanoparticles exhibit antidiabetic activity in L6 rat skeletal muscle cells. Materials Letters. 2019;241:198-201. doi:10.1016/j.matlet.20 19.01 .086

238. Khaleel Basha S, Govindaraju K, Manikandan R, Ahn JS, Bae EY, Singaravelu G. Phytochemical mediated gold nanoparticles and their PTP 1B inhibitory activity. Colloids Surf $B$ Biointerfaces. 2010;75(2):405-409.

239. Ranjous Y, Regdon G, Pintye-Hodi K, Sovany T. Standpoint on the priority of TNTs and CNTs as targeted drug delivery systems. Drug Discov Today. 2019;24(9):1704-1709. doi:10.1016/j. drudis.2019.05.019

240. Wong BS, Yoong SL, Jagusiak A, et al. Carbon nanotubes for delivery of small molecule drugs. Adv Drug Deliv Rev. 2013;65 (15):1964-2015.

241. Martincic M, Tobias G. Filled carbon nanotubes in biomedical imaging and drug delivery. Expert Opin Drug Deliv. 2015;12 (4):563-581.

242. Ilie I, Ilie R, Mocan T, Tabaran F, Iancu C, Mocan L. Nicotinamide-functionalized multiwalled carbon nanotubes increase insulin production in pancreatic beta cells via MIF pathway. Int J Nanomedicine. 2013;8:3345-3353.

243. Li Z, Zhang Y, Feng N. Mesoporous silica nanoparticles: synthesis, classification, drug loading, pharmacokinetics, biocompatibility, and application in drug delivery. Expert Opin Drug Deliv. 2019;16(3):219-237.

244. Yang G, Phua SZF, Bindra AK, Degradability ZY. Clearance of Inorganic Nanoparticles for Biomedical Applications. Adv Mater. 2019;31(10):e1805730.

245. Croissant JG, Fatieiev Y, Almalik A, Khashab NM, Silica M. Organosilica Nanoparticles: physical Chemistry, Biosafety, Delivery Strategies, and Biomedical Applications. Adv Healthc Mater. 2018;7:4
246. Mohammadpour R, Dobrovolskaia MA, Cheney DL, Greish KF, Ghandehari H. Subchronic and chronic toxicity evaluation of inorganic nanoparticles for delivery applications. Adv Drug Deliv Rev. 2019;144:112-132.

247. Lai F, Schlich M, Pireddu R, Fadda AM, Sinico C. Nanocrystals as Effective Delivery Systems of Poorly Water-soluble Natural Molecules. Curr Med Chem. 2019;26(24):4657-4680.

248. Liversidge GG, Cundy KC. Particle size reduction for improvement of oral bioavailability of hydrophobic drugs: I. Absolute oral bioavailability of nanocrystalline danazol in beagle dogs. Int J Pharm. 1995;125(1):91-97.

249. Chen C, Fu X. Spheroidization on Fructus Mori polysaccharides to enhance bioavailability and bioactivity by anti-solvent precipitation method. Food Chem. 2019;300:125245.

250. Wang Y, Zheng Y, Zhang L, Wang Q, Zhang D. Stability of nanosuspensions in drug delivery. J Control Release. 2013;172 (3):1126-1141.

251. Wang L, Du J, Zhou Y, Wang Y. Safety of nanosuspensions in drug delivery. Nanomedicine. 2017;13(2):455-469.

252. Gao L, Liu G, Ma J, Wang X, Zhou L, Li X. Drug nanocrystals: in vivo performances. Journal of Controlled Release. 2012;160 (3):418-430.

253. Souto EB, Souto SB, Campos JR, et al. Nanoparticle Delivery Systems in the Treatment of Diabetes Complications. Molecules. 2019;24:23.

254. Rho JG, Han HS, Han JH, et al. Self-assembled hyaluronic acid nanoparticles: implications as a nanomedicine for treatment of type 2 diabetes. J Control Release. 2018;279:89-98.

255. Rahimi HR, Mohammadpour AH, Dastani M, et al. The effect of nano-curcumin on $\mathrm{HbA} 1 \mathrm{c}$, fasting blood glucose, and lipid profile in diabetic subjects: a randomized clinical trial. Avicenna Journal of Phytomedicine. 2016;6(5):567-577.

256. Asadi S, Gholami MS, Siassi F, Qorbani M, Khamoshian K, Sotoudeh G. Nano curcumin supplementation reduced the severity of diabetic sensorimotor polyneuropathy in patients with type 2 diabetes mellitus: A randomized double-blind placebo- controlled clinical trial. Complement Ther Med. 2019;43:253-260.

257. Veiseh O, Tang BC, Whitehead KA, Anderson DG, Langer R. Managing diabetes with nanomedicine: challenges and opportunities. Nat Rev Drug Discov. 2015;14(1):45-57.
International Journal of Nanomedicine

\section{Publish your work in this journal}

The International Journal of Nanomedicine is an international, peerreviewed journal focusing on the application of nanotechnology in diagnostics, therapeutics, and drug delivery systems throughout the biomedical field. This journal is indexed on PubMed Central, MedLine, CAS, SciSearch ${ }^{\mathbb{}}$, Current Contents ${ }^{\mathbb{R}} /$ Clinical Medicine,
Journal Citation Reports/Science Edition, EMBase, Scopus and the Elsevier Bibliographic databases. The manuscript management system is completely online and includes a very quick and fair peer-review system, which is all easy to use. Visit http://www.dovepress.com/ testimonials.php to read real quotes from published authors. 